\title{
The seasonal and spatial variability of small-scale turbulence at the Iberian margin
}

\author{
by Toby J. Sherwin ${ }^{1,2}$, Mark E. Inall ${ }^{3}$ and Ricardo Torres ${ }^{2}$
}

\begin{abstract}
Turbulence measurements were made off the northwest coast of Spain in January and August 1998. In winter the water column was vertically mixed to about 100 to $150 \mathrm{~m}$, due to the combined effects of the vertical convection of warm northward-moving water and wind stress. A highly dissipative surface boundary layer was present at all times to a depth (of about $20 \mathrm{~m}$ ) that correlated well with the local wind and wave amplitude. Below this layer dissipation levels decreased from about $10^{-7} \mathrm{~m}^{2} \mathrm{~s}^{-3}$ at a rate that was commensurate with 'law of the wall' boundary theory. Near the coast local brackish surface stratification served to depress mixing below the pycnocline.In summer, when the water column was thermally stratified, average dissipation levels were typically an order of magnitude smaller than in winter, even though the wind stress in the ocean was of similar magnitude. Bursts of enhanced mixing were occasionally observed in an internal wave field on the shelf. Dissipation levels were higher on the northern side of an upwelling filament (up to $10^{-7} \mathrm{~m}^{2} \mathrm{~s}^{-3}$ ) than in other parts of the ocean. Although eddy viscosity levels on the shelf and in the ocean were almost identical (about $\left.8 \mathrm{~cm}^{2} \mathrm{~s}^{-1}\right)$, eddy diffusion on the shelf $\left(0.37 \mathrm{~cm}^{2} \mathrm{~s}^{-1}\right)$ was about three times larger than in the ocean. This may indicate a higher frequency of mixing events on the shelf. The summer data were used to determine a mixing length (of about $0.3 \pm 0.05 \mathrm{~m}$ ) using an algorithm that mimicked the way that turbulence closure models compute dissipation from vertical shear and buoyancy over grid scales of several meters. The correlation between dissipation and the gradient Richardson number was poor and it is suggested that at the scales of the observations, and of some models, buoyancy is just as likely to act as a source of mixing as it is to act as a sink.
\end{abstract}

\section{Introduction}

One of the objectives of the EU MAST project OMEX II was to measure turbulent dissipation off the northwest coast of Spain in order to help with the parameterization of mixing in local numerical models. Oceanographic conditions in the surface waters of the region vary considerably with the seasons: in winter a warm current (sometimes called the 'Navidad') with water mixed to about $100 \mathrm{~m}$, pushes northward along the Iberian Coast (Fig. 1); in summer upwelling winds (from the north) force enhanced southward flows

1. Centre for Applied Oceanography, University of Wales - Bangor, Menai Bridge, Anglesey LL59 5EY, United Kingdom.

2. Present address: Westlakes Research Institute, Westlakes Science and Technology Park, Moor Row, Cumbria CA24 3LN, United Kingdom.email: toby.sherwin@westlakes.ac.uk

3. University of the Highlands and Islands Project, SAMS P. O. Box 3, Oban, Argyll PA34 4AD, United Kingdom. 


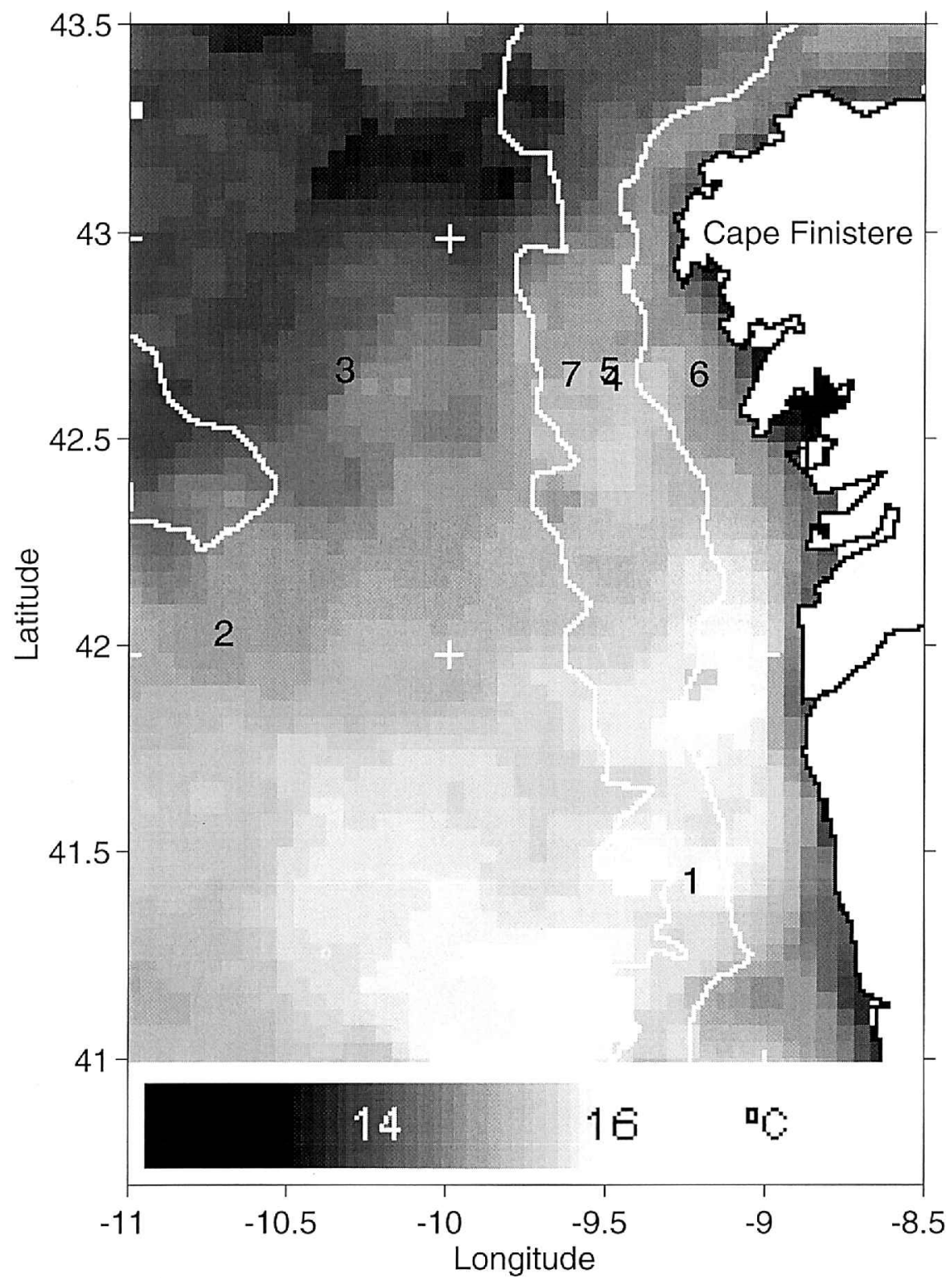

Figure 1. Composite of AVHRR sea surface temperatures off the northwest coast of Spain between 4 and 10 Jan 1998. A broad swath of warm water (lighter shading) can be seen pushing northward almost as far as Cape Finistere. The approximate $200 \mathrm{~m}$ and $1000 \mathrm{~m}$ isobaths and the positions of the winter FLY observations are also shown. Crossing points of the main lines of latitude and longitude are indicated with a ' + ', and a temperature scale is shown. 


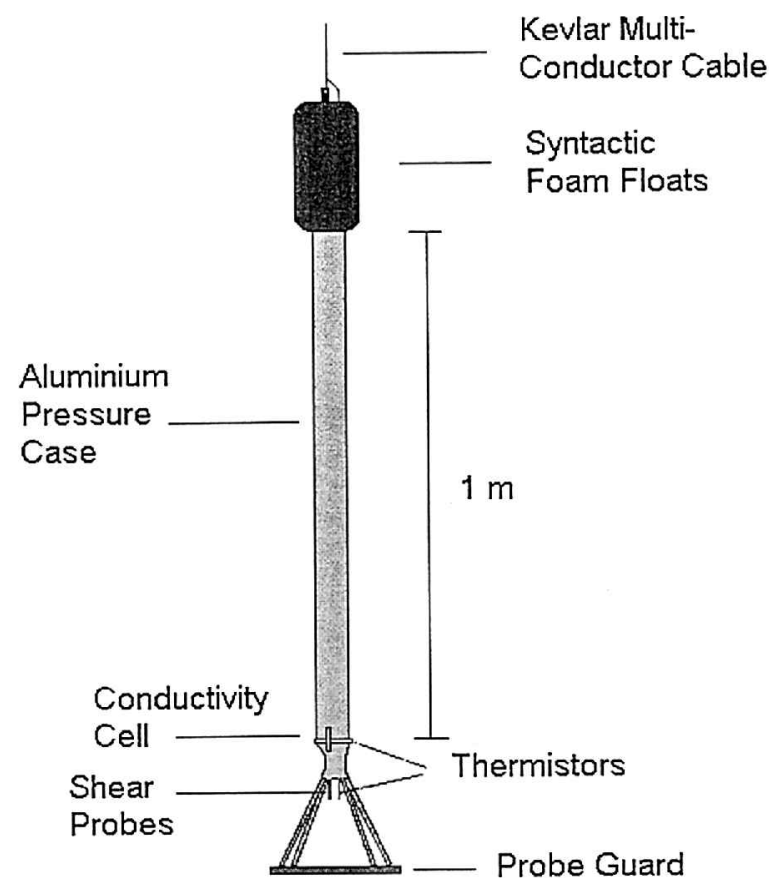

Figure 2. Schematic diagram of the FLY probe.

along the shelf edge, which at various locations are ejected westward to appear as filaments in satellite images. At the shelf edge, density is generally uniform with depth in winter but, in summer, the water column stratifies to allow internal tides and nonlinear internal waves to be generated which propagate from the shelf toward the coast.

The observation program was designed around two cruises (in winter and summer). One of the aims of the program was to establish baseline estimates of dissipation and vertical diffusion in a variety of conditions. An analysis of these observations, and a consideration of how they might be used in numerical models, is presented here.

\section{The dissipation probe}

The dissipation FLY probe (Fig. 2) is the most recent of an evolving line of instruments developed from an original by Osborn (1974). At the heart of the system are two fast response shear sensors made of a small piezoceramic bimorph plate that responds to a shear strain by generating a voltage, in a manner similar to a gramophone cartridge. The plate is embedded in a plug of soft epoxy having an airfoil shape. The probe is able to detect shears of between 0 and $4 \mathrm{~s}^{-1}$ with a precision of $\pm 5 \%$ and a response length of 0.01-0.02 m (Dewey et al., 1987).

The probe is designed to be dropped from the stern of a slowly moving ship. Data are relayed on board through a cable that decouples it from the movement of the ship. As the 
probe falls through the water, with velocity $V$, it experiences a sideways lift force, $F$, due to the horizontal component of the turbulent velocity fluctuations, $u$, which is given by (Crawford, 1976)

$$
F=\frac{1}{2} \rho \tilde{V}^{2} A \sin 2 \phi
$$

where $\tilde{V}^{2}=V^{2}+u^{2}$ is the apparent velocity past the probe; $A$ is the effective cross-sectional area of the probe; $\rho$ is the density of seawater; and $\phi=\tan ^{-1} u / V$ is the angle of $\tilde{V}$ to the probe. Provided $\phi$ is small $\left(<5^{\circ}\right)$, a condition which is usually attained (Dewey et al., 1987), the instantaneous shear is given by

$$
\frac{\partial u}{\partial z}=\frac{1}{C V^{2}} \frac{\partial \varsigma}{\partial t}
$$

where $C$ is a calibration constant; and s (proportional to $F$ ) is the output voltage from the sensor.

It is common practice to divide the water column into a series of discrete lengths (typically $2 \mathrm{~m}$ ) and estimate the variance or energy in the turbulent shear from

$$
\varepsilon=7.5 v\left\langle\left(\frac{\partial u}{\partial z}\right)^{2}\right\rangle
$$

where the angle brackets indicate an average over distance and $v$ is the kinematic viscosity of seawater $\left(1.049 \times 10^{-6} \mathrm{~m}^{2} \mathrm{~s}^{-1}\right)$. The result is an estimate of turbulent dissipation, $\varepsilon$, i.e. the rate at which turbulence is being dissipated by viscous forces, in units of $\mathrm{m}^{2} \mathrm{~s}^{-3}$. The calculation of $\varepsilon$ needs to be conducted with some care, to account for low wavenumber body movements of the FLY, and attenuation of the high wavenumber part of the signal. Suitable filtering of the time series and boosting of the output are required to produce an acceptable estimate of dissipation.

Since turbulence dissipation is an intermittent process, it is necessary to make a series of profiles (or drops) at each station. Temporal averaging can then be used to produce mean dissipation values (see e.g. Davis, 1996). In addition to measuring dissipation, the FLY also carries temperature and salinity probes (although on the winter cruise the latter did not work) so that in situ measurements of density can be made.

\section{Winter cruise observations}

The winter observations were made between 10 January and 15 January 1998 from the RRS Charles Darwin (Cruise CD110b). Throughout the cruise conditions were very rough and had a detrimental impact on the amount of work that could be done (Fig. 3).

Vertical current shear was measured with a shipborne ADCP and validated by the British Oceanographic Data Center. Unfortunately the instrument returned poor quality data throughout the cruise (probably because of the movement of the ship under the prevailing swell). Meteorological data were measured using a Davis Instruments Weather 


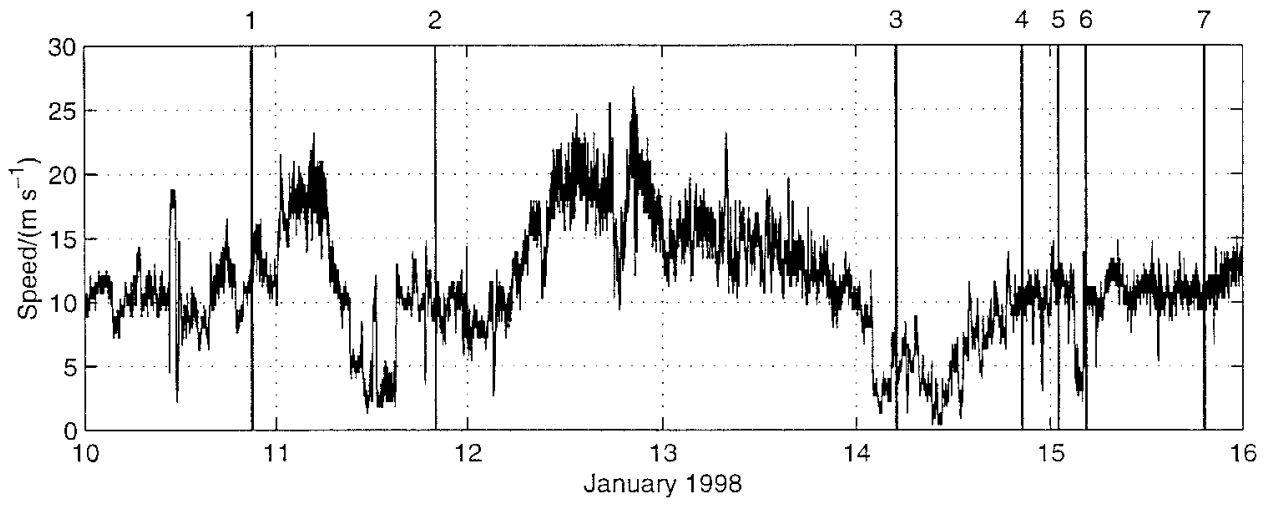

Figure 3. Wind speed in January 1998. The vertical lines indicate the times of the FLY observations.

Monitor II located $3 \mathrm{~m}$ above the superstructure of the ship and about $16 \mathrm{~m}$ above the sea surface. Sea state was observed visually by the deck officers and reported in the ship's log along with meteorological observations. These observations provided a check on the performance of the recording package. No allowance has been made for the apparent wind due to the moving ship. However, the wind measurements of interest here were made during the period of FLY deployment, when the ship was moving at typically only $0.25 \mathrm{~m} \mathrm{~s}^{-1}$.

The cruise encountered some strong winds and large seas and the FLY probe could only be deployed when the conditions had moderated sufficiently. In total only seven measurement series (61 drops) were possible (see Table 1). During the observation periods the mean wind speed was typically $10 \mathrm{~m} \mathrm{~s}^{-1}$, although at most other times it was greater than this. Local waves had a peak to trough height of between 1 and $2 \mathrm{~m}$, and there was a persistent $7-8 \mathrm{~s}$ period swell with a height of typically $5 \mathrm{~m}$. Most of the measurements were made in the deep ocean, although two (Series 4 and 5) were made at the shelf edge and one (Series 6) on the shelf itself.

The majority of the observations were made at the northernmost extent of the Navidad (Fig. 1). At most of the stations, the density profile was dominated by temperature, with salinity playing only a secondary role. At Series 6 near the coast, however, there was a strong salinity-dominated pycnocline with surface salinities of about 33 increasing to about 36 at $70 \mathrm{~m}$ with a simultaneous temperature drop of about $1^{\circ} \mathrm{C}$ (Fig. 4). In the south of the region near the shelf slope (Series 1) surface temperatures were about $15.9^{\circ} \mathrm{C}$ and the surface mixed layer extended to just over $100 \mathrm{~m}$ (Fig. 5). To the northwest of this point the surface temperatures were cooler $\left(14.3\right.$ to $15.6^{\circ} \mathrm{C}$, Table 1$)$ and the layer extended a little deeper (to between 130 and $150 \mathrm{~m}$ ).

The rough conditions seem to have affected the performance of the probe near the surface. In calm conditions in a quarry reservoir it reached a terminal velocity in about $3 \mathrm{~m}$, after which its tilt angle was always less than $3^{\circ}$. During the winter cruise, however, the 
Table 1. Summary of environmental observations during the winter cruise.

\begin{tabular}{|c|c|c|c|c|c|c|c|}
\hline Series & 1 & 2 & 3 & 4 & 5 & 6 & 7 \\
\hline Date (January) & 10 & 11 & 14 & 14 & 15 & 15 & 15 \\
\hline Start Time & 2107 & 2020 & 0458 & 2034 & 0106 & 0430 & 1914 \\
\hline \multirow[t]{2}{*}{ Position } & $41^{\circ} 26^{\prime} \mathrm{N}$ & $42^{\circ} 02^{\prime} \mathrm{N}$ & $42^{\circ} 41^{\prime} \mathrm{N}$ & $42^{\circ} 39^{\prime} \mathrm{N}$ & $42^{\circ} 40^{\prime} \mathrm{N}$ & $41^{\circ} 39^{\prime} \mathrm{N}$ & $42^{\circ} 40^{\prime} \mathrm{N}$ \\
\hline & $9^{\circ} 14^{\prime} \mathrm{W}$ & $10^{\circ} 04^{\prime} \mathrm{W}$ & $10^{\circ} 19^{\prime} \mathrm{W}$ & $9^{\circ} 14^{\prime} \mathrm{W}$ & $9^{\circ} 30^{\prime} \mathrm{W}$ & $9^{\circ} 13^{\prime} \mathrm{W}$ & $9^{\circ} 36^{\prime} \mathrm{W}$ \\
\hline Total depth (m) & 2000 & 2500 & 2800 & 250 & 250 & 100 & 1000 \\
\hline No of drops & 6 & 15 & 6 & 8 & 8 & 12 & 6 \\
\hline Wind speed $\left(\mathrm{m} \mathrm{s}^{-1}\right)$ & 14.2 & 9.6 & 5.6 & 10.7 & 11.5 & 10.4 & 11.0 \\
\hline Wave ht (m) & 2 & 2 & 0.5 & 0.75 & 1 & 1.5 & 2 \\
\hline Swell ht (m) & 4.5 & 6 & 8 & 5 & 5 & 5 & 5.5 \\
\hline Swell period (s) & 8 & 8 & 7 & 7 & 7 & 7 & 7 \\
\hline $\operatorname{SBL}(\mathrm{m})$ & 22 & 22 & 18 & 18 & 20 & 16 & 24 \\
\hline$u^{*}\left(\mathrm{~m} \mathrm{~s}^{-1}\right)$ & 0.018 & 0.011 & 0.007 & 0.013 & 0.014 & 0.012 & 0.013 \\
\hline$u^{*^{\prime}}\left(\mathrm{m} \mathrm{s}^{-1}\right)$ & 0.014 & 0.010 & 0.010 & 0.015 & 0.018 & 0.006 & 0.016 \\
\hline$\varepsilon_{12}\left(10^{-5} \mathrm{~m}^{2} \mathrm{~s}^{-3}\right)$ & 5.5 & 5.0 & 1.7 & 0.5 & 2.6 & 1.4 & 20.7 \\
\hline Air temp $\left({ }^{\circ} \mathrm{C}\right)$ & 17.4 & 14.8 & 10.6 & 13.7 & 14.0 & 13.9 & 14.8 \\
\hline$\theta_{D}\left({ }^{\circ} \mathrm{C}\right)$ & 9.7 & 11.0 & 6.9 & 8.3 & 9.0 & 10.1 & 12.0 \\
\hline$\theta_{12}\left({ }^{\circ} \mathrm{C}\right)$ & 15.89 & 14.93 & 14.32 & 15.62 & 15.58 & 14.37 & 15.14 \\
\hline$Q\left(\mathrm{~W} \mathrm{~m}^{-2}\right)$ & -788 & -260 & -248 & -578 & -587 & -325 & -257 \\
\hline$B\left(10^{-5} \mathrm{~m}^{-2} \mathrm{~s}^{-3}\right)$ & -37 & -12 & -12 & -27 & -27 & -15 & -12 \\
\hline$L_{\mathrm{MO}}(\mathrm{m})$ & -0.03 & -0.03 & -0.02 & -0.03 & -0.04 & -0.02 & -0.07 \\
\hline
\end{tabular}

probe often dropped 50 to $100 \mathrm{~m}$ before achieving its terminal velocity, although in general the tilt became less than $3^{\circ}$ at a much shallower depth (typically $20 \mathrm{~m}$ ). On many occasions the fall speed had an oscillating component with an amplitude of up to $10 \mathrm{~cm} \mathrm{~s}^{-1}$ and a similar period to that of the swell. Observations above $12 \mathrm{~m}$ depth have been ignored because (a) there is a possibility that the probe experienced excessive sideways movement in the top $10 \mathrm{~m}$, which could have caused $\phi>3^{\circ}$ (see 1), and (b) collisions with bubbles due to breaking waves may have invalidated some of the measurements near the surface.

High dissipation activity (from about $10^{-5} \mathrm{~m}^{2} \mathrm{~s}^{-3}$ to over $10^{-4} \mathrm{~m}^{2} \mathrm{~s}^{-3}$ ) was invariably encountered in a surface boundary layer (SBL) at all stations (Fig. 5). Although values for $\varepsilon$ of order $10^{-4} \mathrm{~m}^{2} \mathrm{~s}^{-3}$ are high, they are not excessive - Anis and Moum (1995), for example, observed larger values during $13 \mathrm{~m} \mathrm{~s}^{-1}$ winds with $3 \mathrm{~m}$ high waves. There was a general tendency for dissipation levels to decrease steadily from the surface down to the thermocline, at which depth on many occasions there was a significant decline in mixing levels (see e.g. Series 3, 4 and 1, Fig. 5). All series except 2 and 6 tended to have reasonably high dissipation levels below the SBL (of order $10^{-7} \mathrm{~m}^{2} \mathrm{~s}^{-3}$ ).

Overall the profiles agree in a qualitative sense with other observations (e.g. Anis and Moum, 1995; Oakey and Elliott, 1982) and with theoretical descriptions of dissipation in homogeneous water in the presence of waves (e.g. Craig and Banner, 1994; Terray et al., 1996).

\section{a. The surface boundary layer}

Within the SBL, turbulence is largely generated by breaking waves and carried downward by diffusive processes. The depth of the layer is generally thought to be quite 


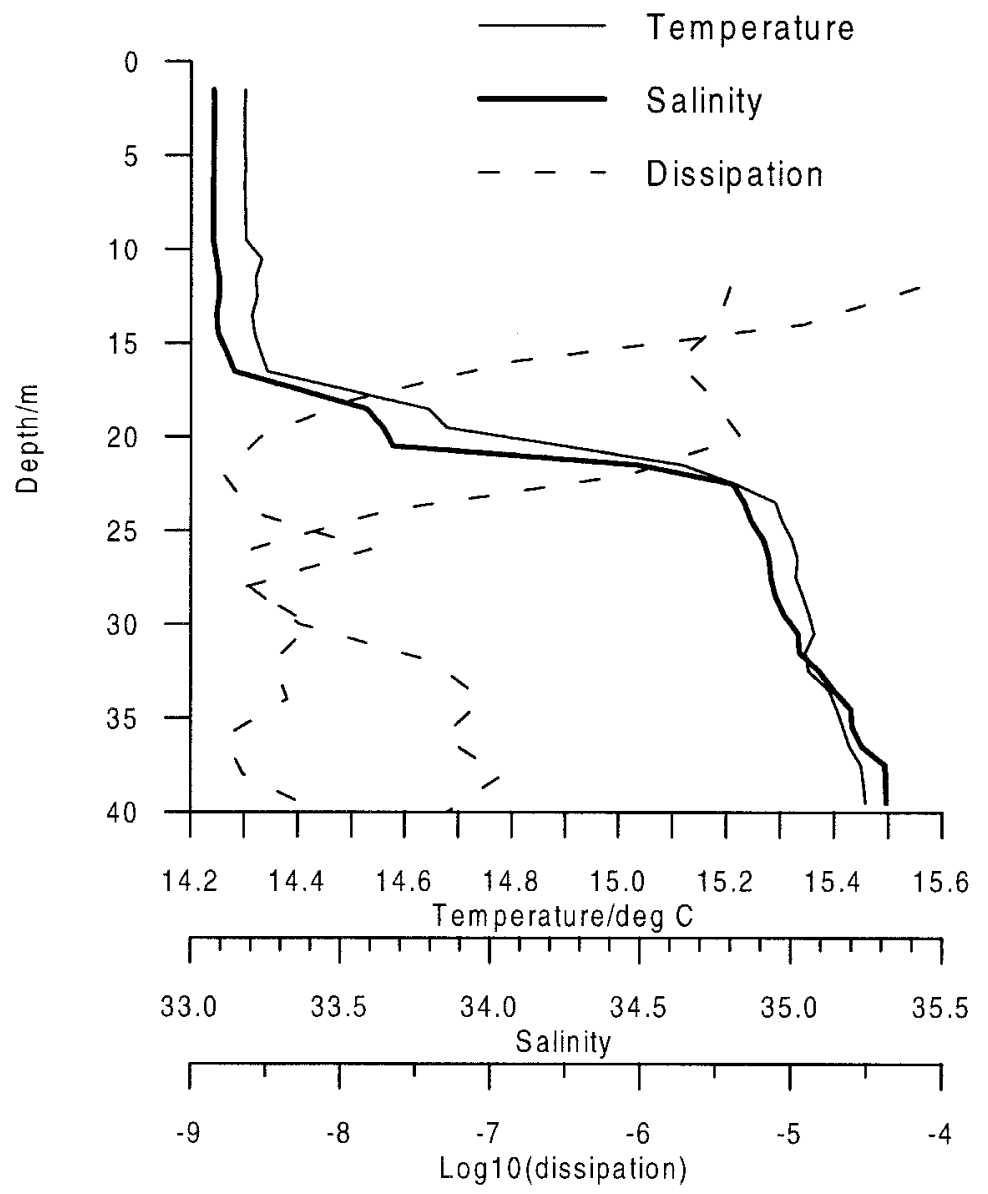

Figure 4. Profiles at Series 6 on the shelf on 15 Jan. Temperature and salinity from a CTD cast at $0557 \mathrm{~h}$; dissipation profiles averaged over $2 \mathrm{~m}$ intervals at $0450 \mathrm{~h}$ and $0510 \mathrm{~h}$.

shallow (for example, Terray et al. (1996) suggested that it is of the order of the significant wave height). In our observations it was much deeper than this (between 18 and $24 \mathrm{~m}$ ). The CTD observations at Series 6, which was located in salinity stratified waters near the coast, show an SBL of about $16 \mathrm{~m}$ that corroborates the depth derived from the dissipation measurements (see Fig. 4). Craig and Banner (1994) have argued that dissipation near the surface should decay in proportion to $z^{-4}$ (where $z$ is depth), but the drop in dissipation at the base of the SBL was significantly sharper than that (see Fig. 5).

The degree of mixing at a depth of $12 \mathrm{~m}, \varepsilon_{12}$, and the thickness of the SBL in the wellmixed ocean correlate well each other, and with the height of wind waves, when Series 6 is ignored (Fig. 6). A similar result applies to the strength of the wind, although the correlation is weaker. By contrast SBL statistics were poorly correlated with either (i) the 

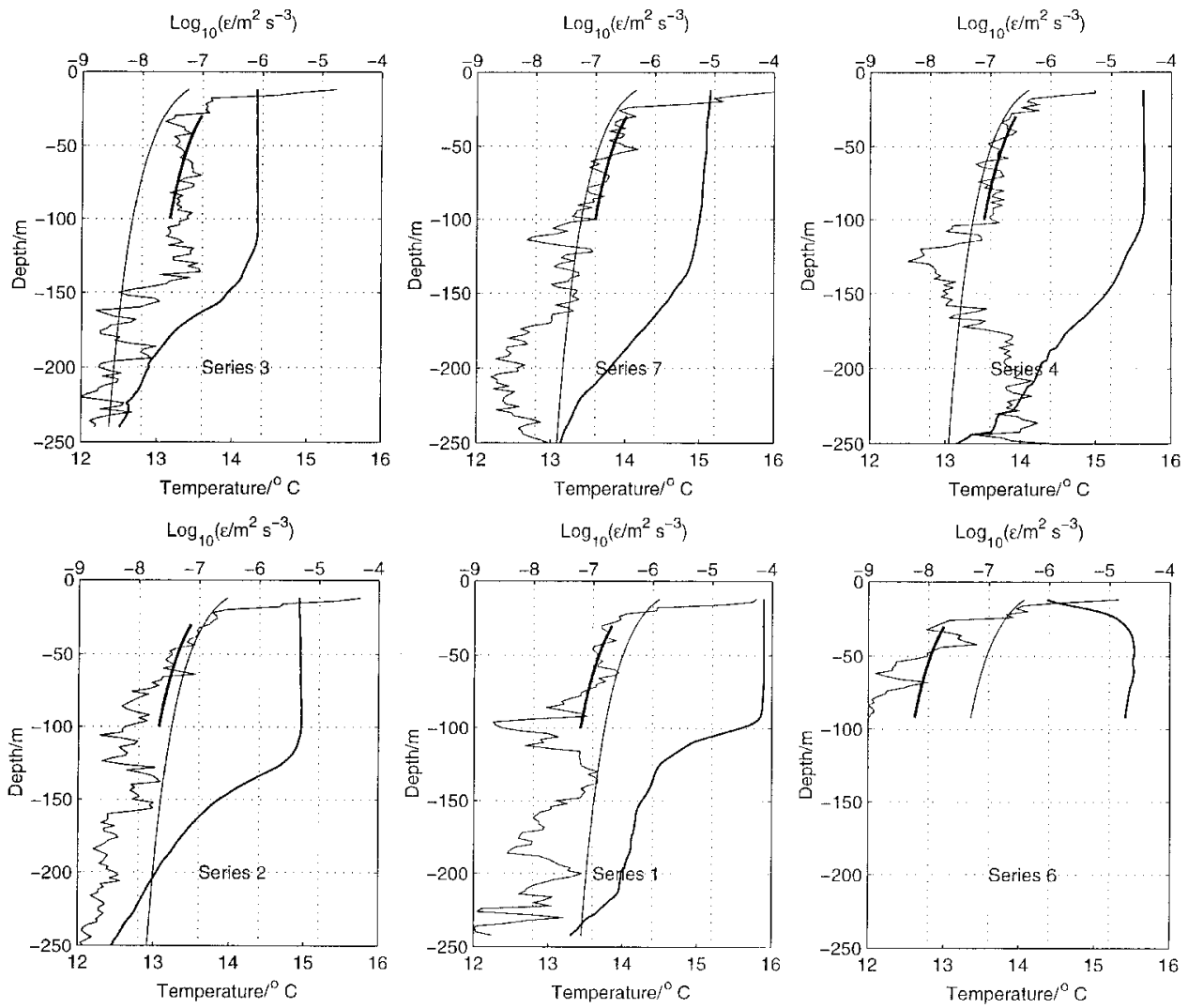

Figure 5. Profiles of dissipation ( $\varepsilon$, thin noisy line), temperature (broader smoother line) and two estimates of $\varepsilon=u^{* 3} / \kappa z$ (Eq. 4). For the long thin line $u^{*}$ is derived from $W$ whilst the thicker line is derived from a least squares fit to $\varepsilon$ between 30 and $100 \mathrm{~m}$. The data are shown for the mean values of all series except 5 and are placed in an approximate geographical arrangement.

size of the swell, or (ii) the differences between sea surface temperature and air or dew point temperatures (Table 1).

The swell may have caused the probe to overestimate the depth of the SBL. If the thickness of the SBL changed only slowly, then its base would have undulated with the swell. Variations in the observed pressure from a typical 7-second swell will have been significantly attenuated below about $12 \mathrm{~m}$, so the SBL would have appeared to be thicker beneath the troughs of the swell. Since the average of a series of dissipation observations at any particular depth is dominated by isolated large events, this overestimate could be up to half the swell height (i.e. $3 \mathrm{~m}$ ).

\section{b. Dissipation beneath the boundary layer}

In many situations dissipation beneath the SBL has been found to decrease inversely with distance at a rate determined by the 'law of the wall.' This 'law' was originally used 

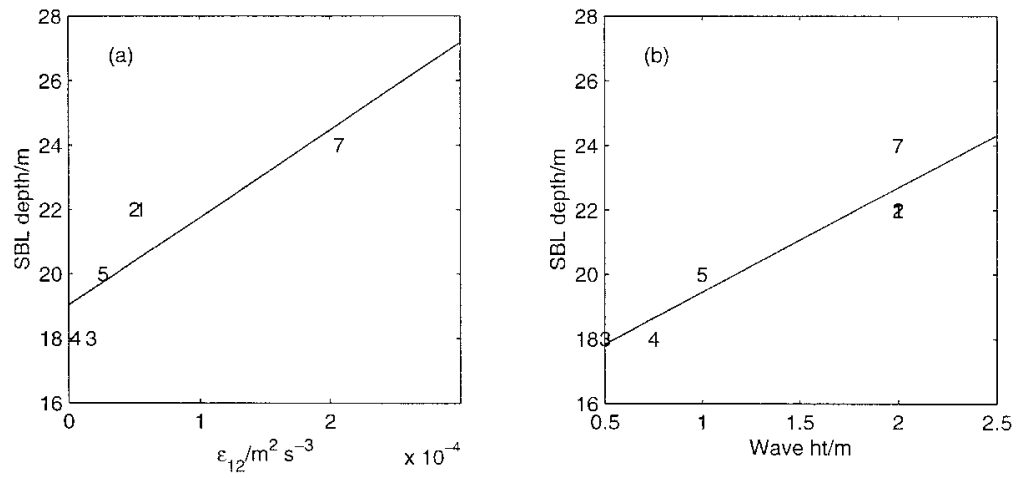

Figure 6. Depth of the SBL in winter against (a) dissipation at $12 \mathrm{~m}$ and (b) wave height, for Series 1 to 5 and 7.

for the seabed, but more recently it has been applied to the sea surface (e.g. Terray et al., 1996). It assumes that dissipation balances the local production of turbulent kinetic energy due to the shear induced by wind stress:

$$
\varepsilon=u^{* 3} / \kappa z \text {. }
$$

Here $\kappa$ is von Karman's constant (0.4) and $u^{*}$ is a friction velocity, which is related to the surface wind stress by

$$
\tau=\rho_{w} u^{* 2}=\rho_{a} C_{D} W^{2}
$$

where $\rho_{w}$ and $\rho_{a}$ are the densities of water and air; $C_{D}$ is a drag coefficient and $W$ is the wind speed. Large and Pond (1981) suggest that when the atmosphere is neutrally stable and $W$ is measured $10 \mathrm{~m}$ above the sea surface:

$$
\begin{aligned}
C_{D} & =1.14 \times 10^{-3} \text { for } 4<W \leq 10 \mathrm{~m} \mathrm{~s}^{-1} \\
& =(0.49+0.065 \mathrm{~W}) \text { for } 10<W<26 \mathrm{~m} \mathrm{~s}^{-1} .
\end{aligned}
$$

A consequence of (4) is that $U$ should vary logarithmically with depth, and that the vertical shear is given by

$$
\frac{\partial U}{\partial z}=-\frac{u^{*}}{\kappa z} .
$$

The dissipation profiles were tested against this theory by (i) directly computing $\varepsilon$ from (4), using (5) and (6) to determine $u^{*}$ and assuming that the ship's wind speed observations are a good approximation to $W$; and (ii) applying a least squares fit of (4) to the observations of $\varepsilon$ between 30 and $100 \mathrm{~m}$, to derive an empirical estimate of the friction velocity, $u^{* \prime}$.

The results are summarized in Figure 5 and Table 1. With the exception of the data from Series 6 (on the shelf), there is a close agreement between the two curves and the means of 
$u^{*}$ and $u^{*^{\prime}}$ are within $10 \%$ of each other. This result might seem to confirm that the law of the wall could be applied to the dissipation profiles. However, although there was enhanced shear in the SBL at most stations (except 3 and 4), beneath the layer the shear measured by the ADCP appears to have been approximately uniform (typically $3 \times 10^{-3} \mathrm{~s}^{-1}$ ). (Note that because the quality of these data is poor they are not presented.) Thus the ADCP observations seem to conflict with (7), and the question of whether the dissipation observed below the boundary layer was caused solely by wind-induced shear stress is not fully resolved.

\section{c. The relative importance of convection and wind mixing}

On most occasions the temperature gradient across the air-sea interface was negative, making the upper layers of the sea convectively unstable, so it is probable that convection contributed to the vertical profile of dissipation. The heat flux across the sea surface, $Q$, is determined by the balance between upward (cooling) fluxes due to longwave radiation and evaporation, and downward (warming) radiation from the sun and from clouds. The sensible heat flux can work in either direction. A simple estimate of this flux that is commensurate with the available observations, is given by Simpson and Bowers (1984) as

$$
Q=Q_{s}+\gamma\left(\theta_{D}-\theta_{12}\right)
$$

where $Q_{S}$ is the solar flux at sea level; $\gamma$ is a thermal exchange coefficient; $\theta_{D}$ is the atmospheric dew point temperature and $\theta_{12}$ is the sea-surface temperature (here taken at $12 \mathrm{~m}$ ). The RHS of (8), which was derived empirically, parameterizes all processes in the heat flux.

For the range of the observed values of $\theta_{D}$ and $\theta_{12} \gamma \approx 16.2+0.55 W^{2}$ (where $W$ is in $\mathrm{m} \mathrm{s}^{-1}$ ). Furthermore $Q_{S}=0$ since all the casts took place during the hours of darkness. Thus, to first order, variations in the heat flux were determined by $\left(\theta_{D}-\theta_{12}\right)$ and the wind stress. Since $\theta_{D}$ was always significantly less than $\theta_{12}$, there was a large upward heat flux which ranged from about 250 to nearly $800 \mathrm{~W} \mathrm{~m}^{-2}$ (see Table 1 ).

The form of (8) means that both wind/wave and convective mixing increase with wind speed. Nevertheless, there are important differences between the two mechanisms: wind/wave mixing forces mechanical stirring in the surface layers, with energy scales that cascade down to those of the observed dissipation; convection, on the other hand, applies a potential energy anomaly which drives large overturns that can penetrate as far as the pycnocline, but which create relatively small amounts of dissipative energy (e.g. Turner, 1979, Chapter 9). One way of comparing the two processes at the surface is to use the Monin-Obukhov length scale (e.g. Phillips, 1977, p. 283)

$$
L_{M O}=\frac{u^{* 3} / \kappa}{B}
$$

where $B=g \alpha_{\theta} Q / C_{P} \rho \mathrm{m}^{2} \mathrm{~s}^{-3}$ is the buoyancy flux; $\alpha_{\theta}$ is the thermal coefficient of expansion $\left(\sim 0.196{ }^{\circ} \mathrm{C}^{-1}\right)$; and $C_{P}$ is the specific heat $\left(\sim 4000 \mathrm{~J}\left(\mathrm{~kg}^{\circ} \mathrm{C}\right)^{-1}\right)$. Under 
convective conditions, $L_{M O}$ is negative. During the winter cruise $L_{M O}$ was between -0.07 and $-0.02 \mathrm{~m}$ (Table 1 ), which suggests that night time convection was considerably more effective than wind stress in mixing the region below the SBL.

\section{Dissipation in stratified conditions}

Whilst winter provides a surface-mixed water column in which $\varepsilon \alpha z^{-1}$, in summer the situation is very different. Seasonal stratification enables a range of baroclinic mesoscale processes and internal waves to exist and the vertical shear is unlikely to be related to the surface stress. In addition, local stratification can suppress the vertical component of turbulence, and the surface layers are convectively stable (the heat flux is generally downward). For these reasons an examination of dissipation in summer conditions requires a different approach to that for winter.

An important parameter of turbulent mixing in stratified fluids is the flux Richardson number, $R_{F}$, which is defined as the ratio of the production of buoyancy to the production of turbulent kinetic energy (TKE) by a background stress (e.g. Tennekes and Lumley, 1997):

$$
R_{F}=\frac{g}{\rho_{0}} \frac{\langle w \rho\rangle}{\langle w u\rangle \partial U / \partial z}
$$

where $\rho_{0}$ is the mean density; $\partial U / \partial z$ is the mean vertical shear; $w, u$, and $\rho$ are the fluctuating parts of vertical velocity, horizontal velocity and density respectively and \langle\rangle are averages over a long period of time. Thus, for example, $\langle w\rangle=\langle\rho\rangle=0$, but $\langle w \rho\rangle \neq 0$.

For practical purposes the fluctuating variables in (10) are normally replaced with exchange coefficients such that

$$
R_{F}=\frac{K_{Z} N^{2}}{A_{Z}(\partial U / \partial z)^{2}}
$$

where $N^{2}=-g / \rho_{0} \partial \rho / \partial z, K_{Z}$ is the vertical eddy diffusion coefficient and $A_{Z}$ is the vertical eddy viscosity coefficient.

The definition given by (10) puts no restriction on the range of $R_{F}$, but for stable stratification (as here) it is positive. Under these conditions mixing in the body of a fluid comes from local shear. Experimental observations suggest that, locally at least, $R_{F}$ increases from a value of 0 when $N^{2}=0$ (Linden, 1979) to roughly 0.25 when $R_{G}=$ $N^{2} /(\partial U / \partial z)^{2}$ is $\geq 0.1$ (McEwan, 1983). Many workers assume that in the ocean $R_{F}$ lies between 0.15 and 0.25 , although the justification for this assumption is far from rigorous (e.g. Osborn, 1980, Gargett and Holloway, 1984).

The gradient Richardson number $\left(R_{G}\right)$ is a measure of the stability of the water column. In practice, observational limitations force $R_{G}$ to be measured over a finite distance, $\Delta z$, as $R_{G}=-\left[g \Delta p / \Delta z / \rho_{0}(\Delta \mathrm{U} / \Delta \mathrm{z})^{2}\right]$ where $\Delta \rho$ and $\Delta U$ are the differences in $\rho$ and $U$ over $\Delta z$. If $R_{G}<1$ mixing is theoretically possible, and if $R_{G}<0.25$ spontaneous mixing will 
almost certainly occur. However, the existence of a large value for $R_{G}$, when measured over a large $\Delta z$, does not preclude the possibility of mixing taking place (perhaps intermittently) on much smaller length scales (see e.g. Turner, 1979, Chapter 10).

The other nondimensional part of (11) is the eddy Prandtl number, $P_{R}=A_{Z} / K_{Z}$. At a molecular level in water, $P_{R} \sim 7$ for simple thermal stratification, and $\sim 700$ for simple saline stratification. However, when (turbulent) eddy exchange coefficients are involved $P_{R}$ can be as low as 1 (which will be found within a local mixing event, for example). McEwan (1983) has suggested that when $\Delta z$ is large compared to the scale of local mixing events, $P_{R}^{-1}$ approximates to the intermittency of such events.

Despite the intermittent and highly time varying nature of oceanic turbulence, it is generally assumed that on the macroscale the system is in steady state. This assumption leads to a balance between the production of turbulent kinetic energy $(P)$, the work done against buoyancy in mixing the water column $(B)$, and dissipation at a molecular scale $(\varepsilon)$. Thus (see also A7)

$$
P=B+\varepsilon .
$$

Now, from the definition of $R_{F}$, and (10) and (11), $P=A_{Z}(\partial U / \partial z)^{2}$ and $B=K_{Z} N^{2}$ so (12) can be rewritten as

$$
K_{Z}=\frac{R_{F}}{1-R_{F}} \frac{\varepsilon}{N^{2}} .
$$

If $R_{F}$ is roughly constant, then (13) leads directly to a derivation of $K_{Z}$ from $\varepsilon$. Osborn (1980) suggests that the formula

$$
K_{Z}=0.2 \varepsilon / N^{2}
$$

should give an upper bound on $K_{Z}$, assuming $R_{F}=0.15$. Eq. 14 has the advantage that $K_{Z}$ can be estimated quite easily from the FLY probe. The equivalent formula for viscosity is

$$
A_{Z}=1.2 \varepsilon / M^{2}
$$

where $M^{2}=(\partial U / \partial z)^{2}$. This expression is less amenable than (14) since it requires simultaneous measurements of the local background shear (which are not possible with the FLY). However, (15) may be used to derive bulk estimates of $A_{Z}$ based on observations of the mean shear from a shipborne ADCP.

\section{Summer cruise observations}

The summer dissipation measurements were made in August 1998, on Charles Darwin Cruise CD114. The observations supported several biological experiments, which included following an array of drifting sediment traps. An overview of the experiment can be found in Joint et al. (2001) and more information on the physical regime and dissipation measurements are given by Barton et al. (2001). 


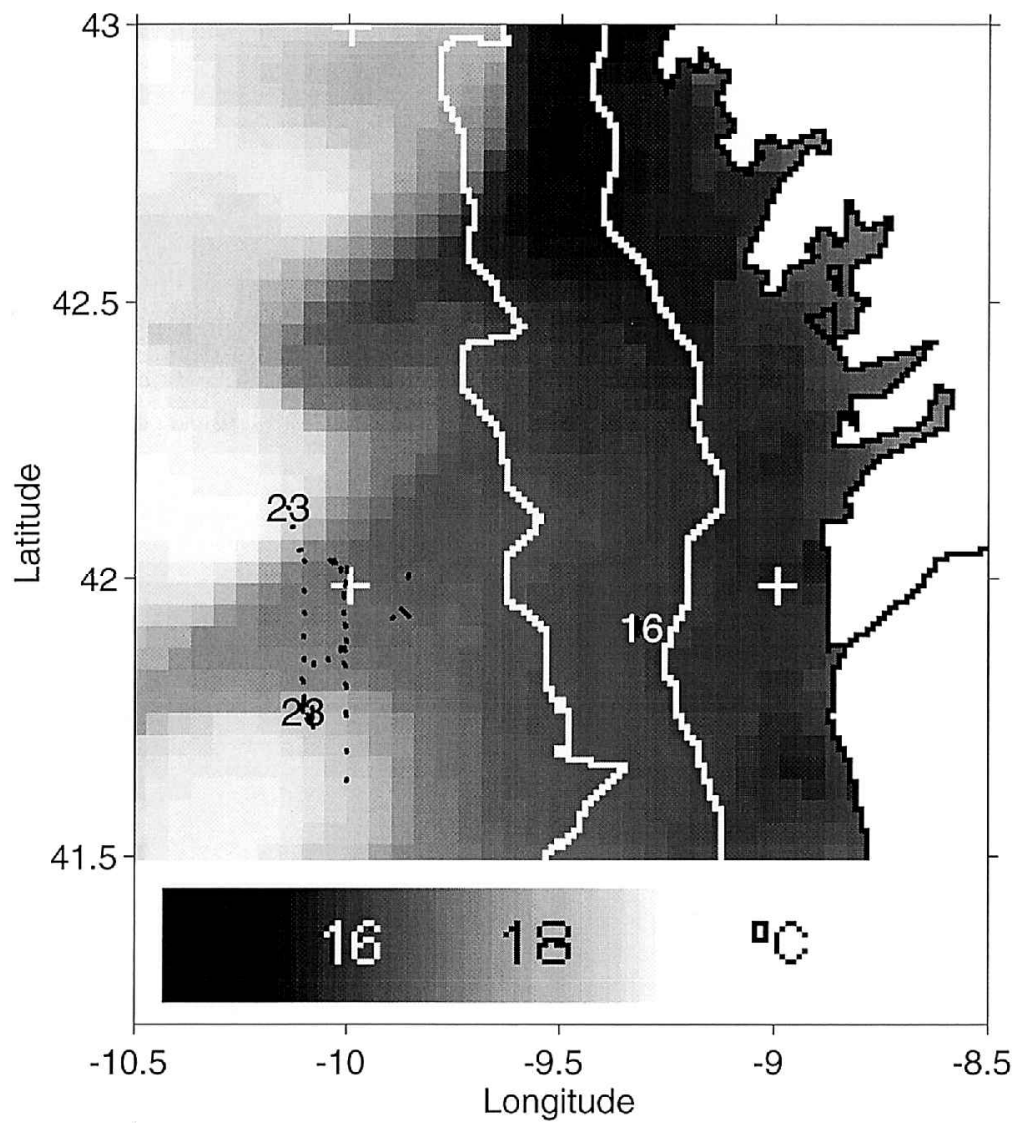

Figure 7. Composite of AVHRR sea surface temperature between 8 and 16 August 1998, during the summer cruise. A cool upwelling filament can be seen as a dark band extending in a south westerly direction from the approximate $200 \mathrm{~m}$ isobath at $42.2 \mathrm{~N}, 9.5 \mathrm{~W}$. Also shown are the positions of the FLY drops on the shelf (Series 16) and in the filament (with the extent of Series 23 indicated). Crossing points of the main lines of latitude and longitude are indicated with a ' + ', and a temperature scale is shown.

Two sets of dissipation observations are reported here (see Fig. 7). The first (Series 16) took place on 8-9 August $5 \mathrm{~km}$ from the shelf edge in the neighborhood of $41^{\circ} 55^{\prime} \mathrm{N}$, $9^{\circ} 18.5,29 \mathrm{~W}$ in about $170 \mathrm{~m}$ water. The second set involved repeated crossings of an upwelling filament about $50 \mathrm{~km}$ from the shelf edge site in deep water.

\section{a. Shelf edge observations}

The dissipation measurements on the shelf formed part of an internal wave experiment lasting about $24 \mathrm{~h}$. During this time the FLY profiled the water column every 6 minutes with breaks of 20 to 30 minutes every 3 to $4 \mathrm{~h}$ for battery recharging. Current velocity 
profiles at $8 \mathrm{~m}$ intervals were determined from the shipborne ADCP, and data with a poor return have been rejected (Torres and Barton, 1999).

The observations took place during spring tides when the semi-diurnal barotropic current had an amplitude of about $0.04 \mathrm{~m} \mathrm{~s}^{-1}$ and wind speeds were light. There was a moderately large internal tide with a vertical amplitude of about $12 \mathrm{~m}$ at $60 \mathrm{~m}$ depth (Fig. 8a) and a velocity difference of about $0.10 \mathrm{~m} \mathrm{~s}^{-1}$ between the upper and lower layers. Superimposed on the internal tide were numerous high frequency waves with amplitudes of up to $10 \mathrm{~m}$ and periods of about $0.5 \mathrm{~h}$.

The maximum shear occurred in the upper part of the water column and was almost coincident with the $15.5^{\circ} \mathrm{C}$ isotherm (Figs. $8 \mathrm{~b}$ and $9 \mathrm{c}$ ). The highest values, up to about $2 \times$ $10^{-2} \mathrm{~s}^{-1}$, occurred during the passage of some large internal waves between about 0630 and 0730 on 9 Aug. This large shear coincided with relatively high recorded values of dissipation, over $10^{-7} \mathrm{~m}^{2} \mathrm{~s}^{-3}$ (Fig. 9d), the position of which followed the fall and subsequent rise of the thermocline.

The average dissipation levels (Fig. 9a) were similar to those observed on the shelf in winter a little farther north (Series 6, Fig. 5), but were typically an order of magnitude smaller than the winter offshore levels. Boundary layers are evident near the surface and seabed. The existence of a SBL is a little surprising given that the winds were light at this time, but it was not a permanent feature in the record and may have been due to internal wave energy being reflected off the sea surface. Between these layers the mean dissipation reached a maximum of about $5 \times 10^{-8} \mathrm{~m}^{2} \mathrm{~s}^{-3}$ at a depth of $30 \mathrm{~m}$, below which it diminished almost linearly with depth to about $5 \times 10^{-9} \mathrm{~m}^{2} \mathrm{~s}^{-3}$ at $125 \mathrm{~m}$. The variation in the mean vertical diffusion coefficient, $K_{Z}$ was somewhat smaller, from about $0.8 \mathrm{~cm}^{2} \mathrm{~s}^{-1}$ at $30 \mathrm{~m}$ to about $0.2 \mathrm{~m}^{2} \mathrm{~s}^{-1}$ at $125 \mathrm{~m}$.

Dissipation levels during the period of intense mixing reached $10^{-7} \mathrm{~m}^{2} \mathrm{~s}^{-3}$ at $40 \mathrm{~m}$, which was about twice the average value for that depth (Fig. 9b), and about an order of magnitude larger than dissipation levels at less active times (Fig. 8c). At the same time $R_{G}$ (averaged over $8 \mathrm{~m}$ ) fell to about 0.5 , which suggests that intense overturning was taking place. By contrast $K_{Z}\left(3 \mathrm{~cm}^{-2} \mathrm{~s}^{-1}\right)$ was about 4 times its mean value for diffusion, mainly because there was concurrently a significant fall in the intensity of stratification (Fig. 9f). This suggests that the mixing broadened the thermocline. Dissipation at $100 \mathrm{~m}$, above the bottom boundary layer, appeared to be particularly weak at this time.

Eddy viscosity levels were generally at least an order of magnitude larger than eddy diffusion ( $7.6 \mathrm{~cm}^{2} \mathrm{~s}^{-1}$, Fig. 9 and Table 2), although during the period of intense mixing $P_{R}$ was arguably close to unity in the thermocline (Fig. 9e).

\section{b. Filament observations}

Over 100 dissipation profiles were observed during the second part of the cruise, which surveyed the oceanic waters immediately adjacent to the shelf. In a good example of these results a $25 \mathrm{~km}$ meridional section across the filament in about $1000 \mathrm{~m}$ of water was transversed along $10^{\circ} 7.5^{\prime} \mathrm{W}$ in the afternoon and evening of 18 August (Series 23, see 
(a) Temperature $/^{\circ} \mathrm{C}$

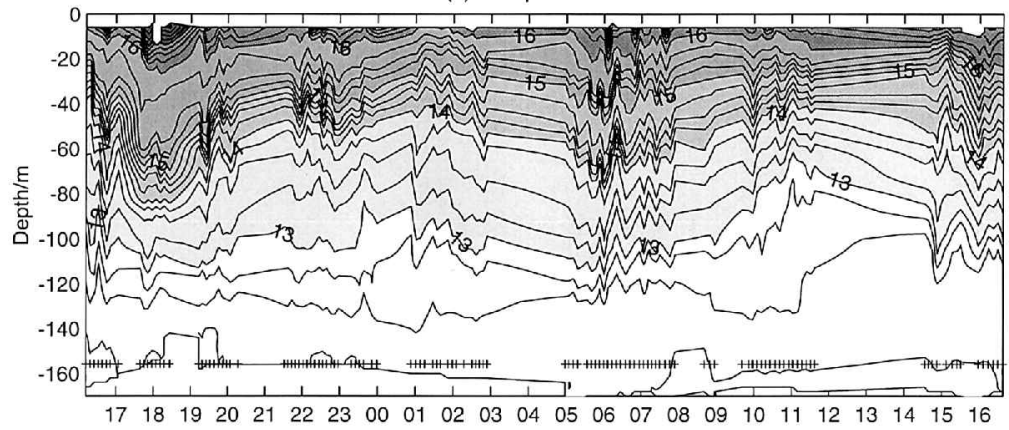

(b) $\log _{10}\left((d \cup / d z)^{2} / s^{-2}\right)$

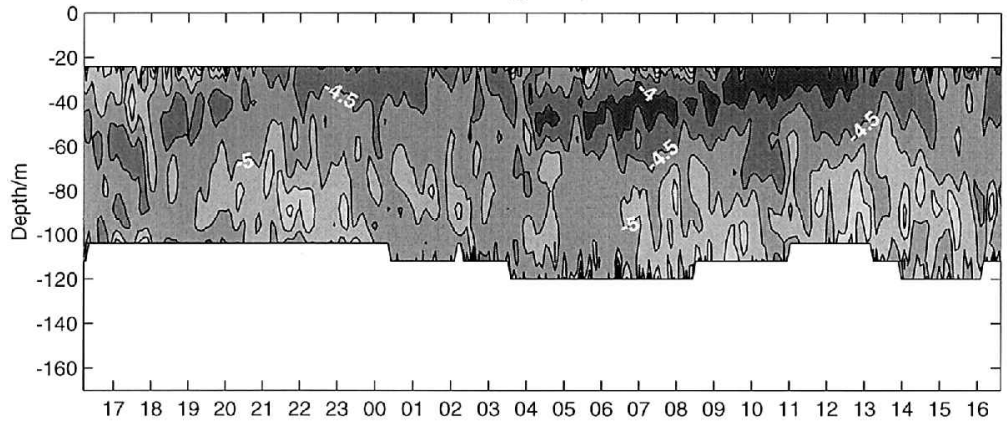

(c) $\log _{10}\left(\varepsilon / \mathrm{m}^{2} \mathrm{~s}^{-3}\right)$

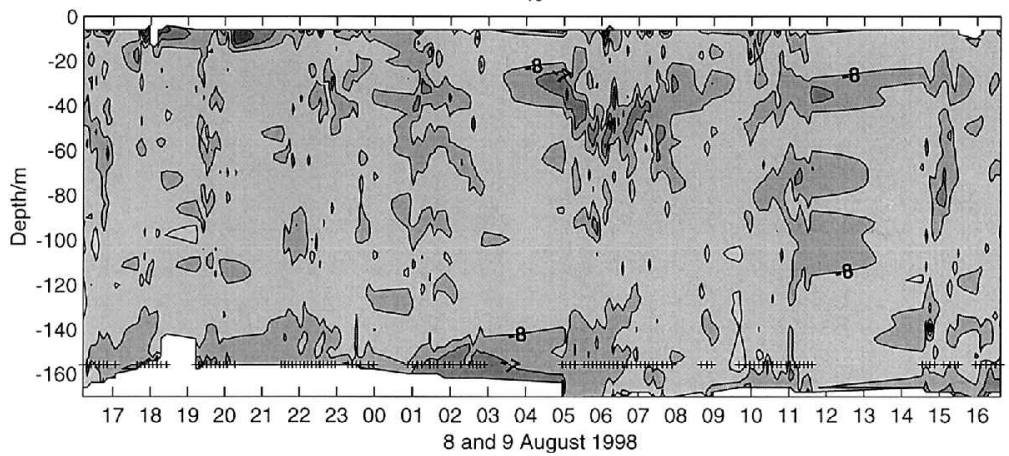

Figure 8. (a) Temperature observed by the FLY probe, (b) shear ${ }^{2}$ observed by the ADCP at 5 min intervals and (c) dissipation from the FLY probe, during Series 16, on the shelf. The crosses along the bottom of (a) and (c) indicate the time of individual FLY drops. The FLY data are smoothed over $6 \mathrm{~m}$ and the ADCP data over $16 \mathrm{~m}$. The ADCP data did not extend as deep as the FLY data. The internal tide and packets of nonlinear waves can be seen, with a region of high shear moving toward the surface after $0500 \mathrm{~h}$ on $9 \mathrm{Aug}$. The $\mathrm{x}$-axis shows the hours of the day. 

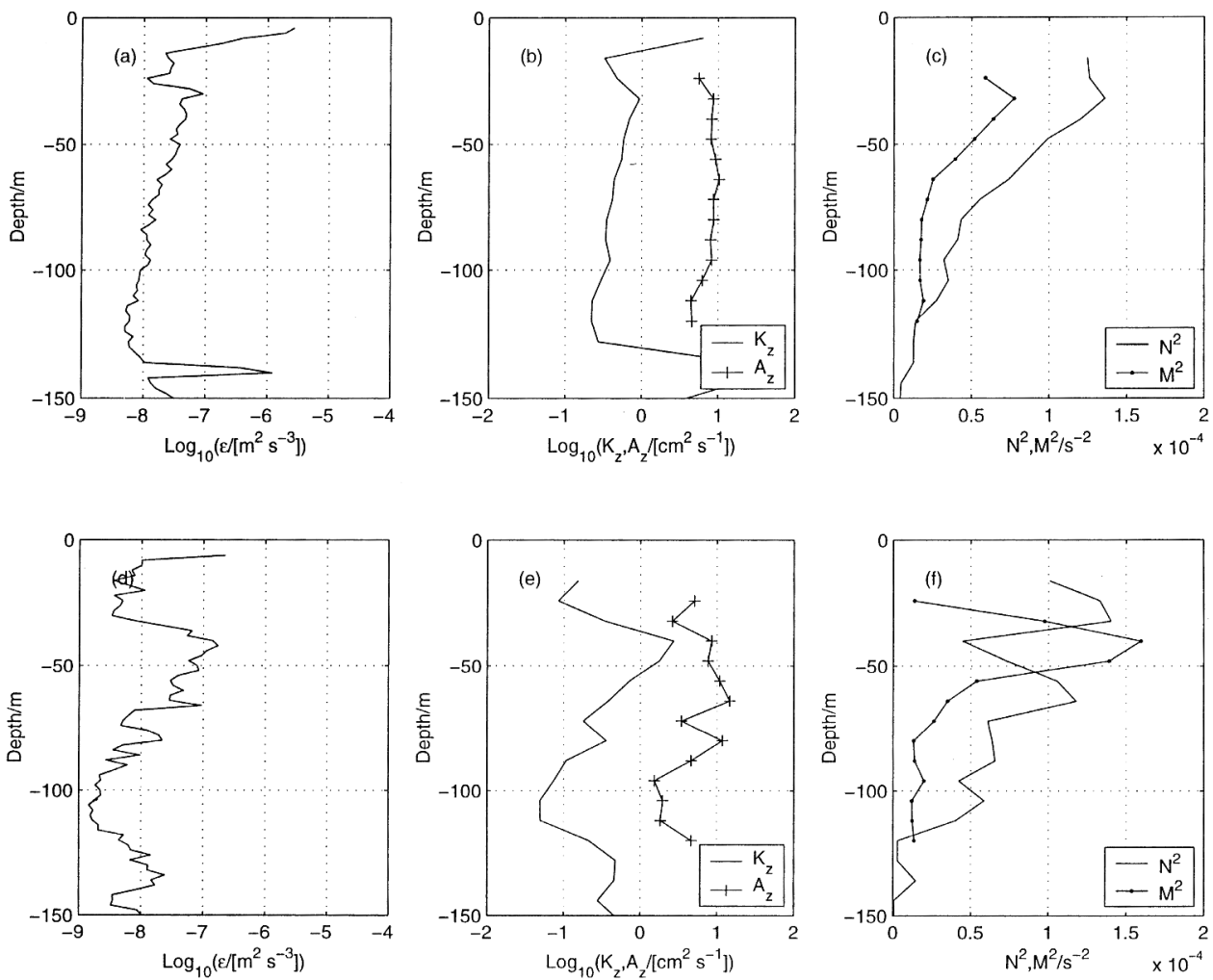

Figure 9. Dissipation (a and d), eddy diffusion and viscosity (b and e), and $N^{2}$ and shear ${ }^{2}$ (c and f) from Series 16. The top row were averaged over all observations and the bottom row between $0500 \mathrm{~h}$ and $0800 \mathrm{~h}$ on $9 \mathrm{Aug}$ when a packet of nonlinear internal waves were observed to pass the site (see Fig 8). Dissipation observations were averaged over $2 \mathrm{~m}$ and the other observations over $8 \mathrm{~m}$.

Figs 7 and 10). During this time a northerly (upwelling favorable) wind of about $10 \mathrm{~m} \mathrm{~s}^{-1}$ was blowing.

Cooler surface water was observed at the center of the surface core of the filament at about $1900 \mathrm{~h}$ (Fig. 10a). To either side there was a well-developed thermocline at a depth of between 40 and $50 \mathrm{~m}$, particularly on the southern side of the filament. However the strongest shears, over $10^{-2} \mathrm{~s}^{-1}$, were mainly found to the north of this point in two bands, one at about $50 \mathrm{~m}$ depth and, another farther north at about $80 \mathrm{~m}(2100 \mathrm{~h}$, Fig 10b). Although $R_{G}$ was generally $>1$ (indicating that mixing could not take place on the scales of the measurements), dissipation levels were above background levels (about $10^{-9} \mathrm{~m}^{2} \mathrm{~s}^{-3}$ ) which indicates that mixing had not been completely suppressed (see Table 2). Nevertheless, $\varepsilon$ was about an order of magnitude smaller than in winter, despite the fact that the wind stress was of similar magnitude. However, relatively high levels (over $10^{-7} \mathrm{~m}^{2} \mathrm{~s}^{-3}$ ) appeared to coincide with the regions of high shears within the thermocline (Fig. 10c). 
Table 2. Summary of observations between about 24 and $136 \mathrm{~m}$ during the summer cruise

$\begin{array}{lccl} & \text { Shelf } & \text { Filament } & \text { Units } \\ \text { No of drops } & 130 & 131 & \\ \varepsilon & 2 \times 10^{-8} & 3 \times 10^{-8} & \mathrm{~m}^{2} \mathrm{~s}^{-3} \\ K_{Z}(\min ) & 0.22 & 0.08 & \mathrm{~cm}^{2} \mathrm{~s}^{-1} \\ K_{Z}(\max ) & 5 & 0.17 & \mathrm{~cm}^{2} \mathrm{~s}^{-1} \\ K_{Z}(\operatorname{mean}) & 0.37 & 0.13 & \mathrm{~cm}^{2} \mathrm{~s}^{-1} \\ A_{Z} & 7.6 & 7.8 & \mathrm{~cm}^{2} \mathrm{~s}^{-1} \\ L_{O} & 0.25 & 0.18 & \mathrm{~m} \\ \text { from }(16): & 0.080 & 0.096 & \\ \quad \alpha & 0.043 & 0.025 & \\ \quad \beta & 5.6 \times 10^{-6} & 9.4 \times 10^{-6} & \\ \text { error in } \varepsilon^{2 / 3} & 0.26 & 0.23 & \mathrm{~m}^{4 / 3} \mathrm{~s}^{-2} \\ L(\text { from } \alpha) & 0.134 & 0.168 & \\ \text { from }(19): & 0.30 & 0.35 & \mathrm{~m} \\ \quad \alpha & 5.6 \times 10^{-6} & 9.5 \times 10^{-6} & \mathrm{~m}^{4 / 3} \mathrm{~s}^{-2} \\ \quad \text { error in } \varepsilon^{2 / 3} & & & \end{array}$

Dissipation levels on the southern side of the core, however, were close to background levels $\left(10^{-9} \mathrm{~m}^{2} \mathrm{~s}^{-3}\right)$ below the thermocline (Fig. 11a), but were about a factor of 5 greater on its northern side at the same depth (Fig. 11b).

On average, eddy diffusion in the ocean $\left(0.13 \mathrm{~cm} \mathrm{~s}^{-1}\right.$, Table 2$)$ was about three times smaller than that encountered on the shelf, possibly because there was less internal wave activity - the ADCP observations suggest that internal waves were less energetic in the ocean than on the shelf. However, eddy viscosity levels were similar to those encountered on the shelf $\left(7.8 \mathrm{~cm}^{2} \mathrm{~s}^{-1}\right)$.

\section{Analysis of model length scales}

A problem for three-dimensional ocean models is that they need to parameterize a vertical mixing field that is forced by a variety of different mechanisms. The differences in these mechanisms can be particularly great when one compares the fine temporal and spatial scales of a train of nonlinear internal waves propagating through a thermally stratified shelf sea with a steady geostrophic current in the frontal region of a mesoscale feature such as an upwelling filament. For turbulence closure models the problem is reduced to one of determining an appropriate mixing length ( $L$, see Appendix). One such length, which can be simply derived from observations made with the FLY profiler measurements, is the Ozmidov scale $L_{O}=\left(\varepsilon N^{-3}\right)^{1 / 2}$ (e.g. Dillon, 1982). However, since models tend to equate dissipation to shear production, it may be more consistent to estimate $L$ from the ADCP data. The observations allow us to calculate $L$ this way, and furthermore to examine an assumption that at the grid scale of a typical ocean model stratification acts as a net sink for dissipation.

In reality, the length scale of overturning is likely to depend on a number of things including the large-scale measures of stratification and shear. However, the $\varepsilon$ and 
(a) Temperature ${ }^{\circ} \mathrm{C}$

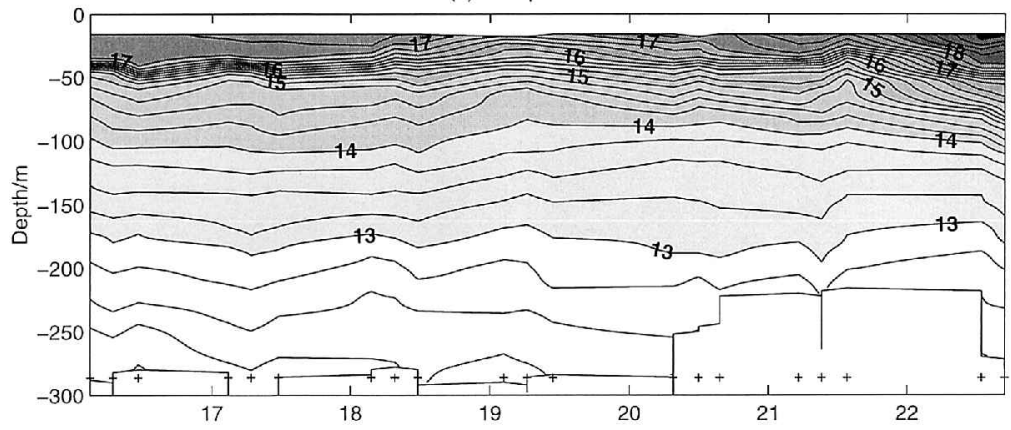

(b) $\log _{10}\left((\mathrm{dU} / \mathrm{dz})^{2} / \mathrm{s}^{-2}\right)$

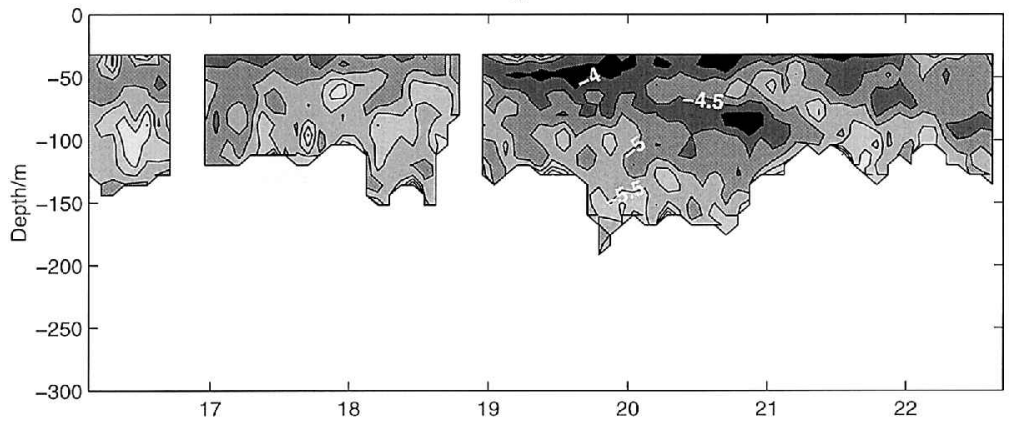

(c) $\log _{10}\left(\varepsilon / \mathrm{m}^{2} \mathrm{~s}^{-3}\right)$

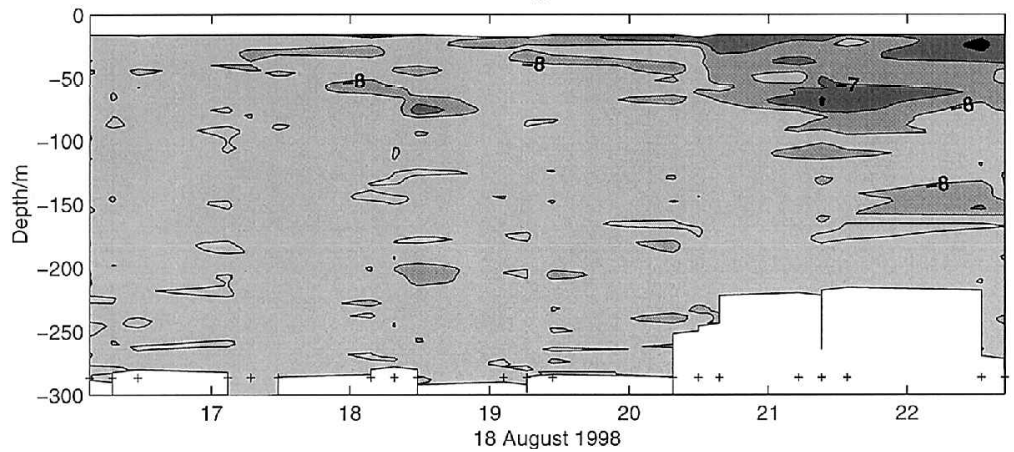

Figure 10. (a) Temperature observed by the FLY probe, (b) shear ${ }^{2}$ observed by the ADCP at 5 min intervals and (c) dissipation from the FLY probe, along Series 23, across the filament at $10^{\circ} 7.5^{\prime} \mathrm{W}$ (see Fig. 7). The FLY data are smoothed over $6 \mathrm{~m}$ and the ADCP data over $16 \mathrm{~m}$. Although the $\mathrm{x}$-axis gives the hours of the day it also approximates to latitude with the southern end of the section at the left-hand side. The crosses along the bottom of (a) and (c) indicate the time of individual FLY drops. The cool center of the filament, as seen by AVHRR, was crossed at about $1900 \mathrm{~h}$. 

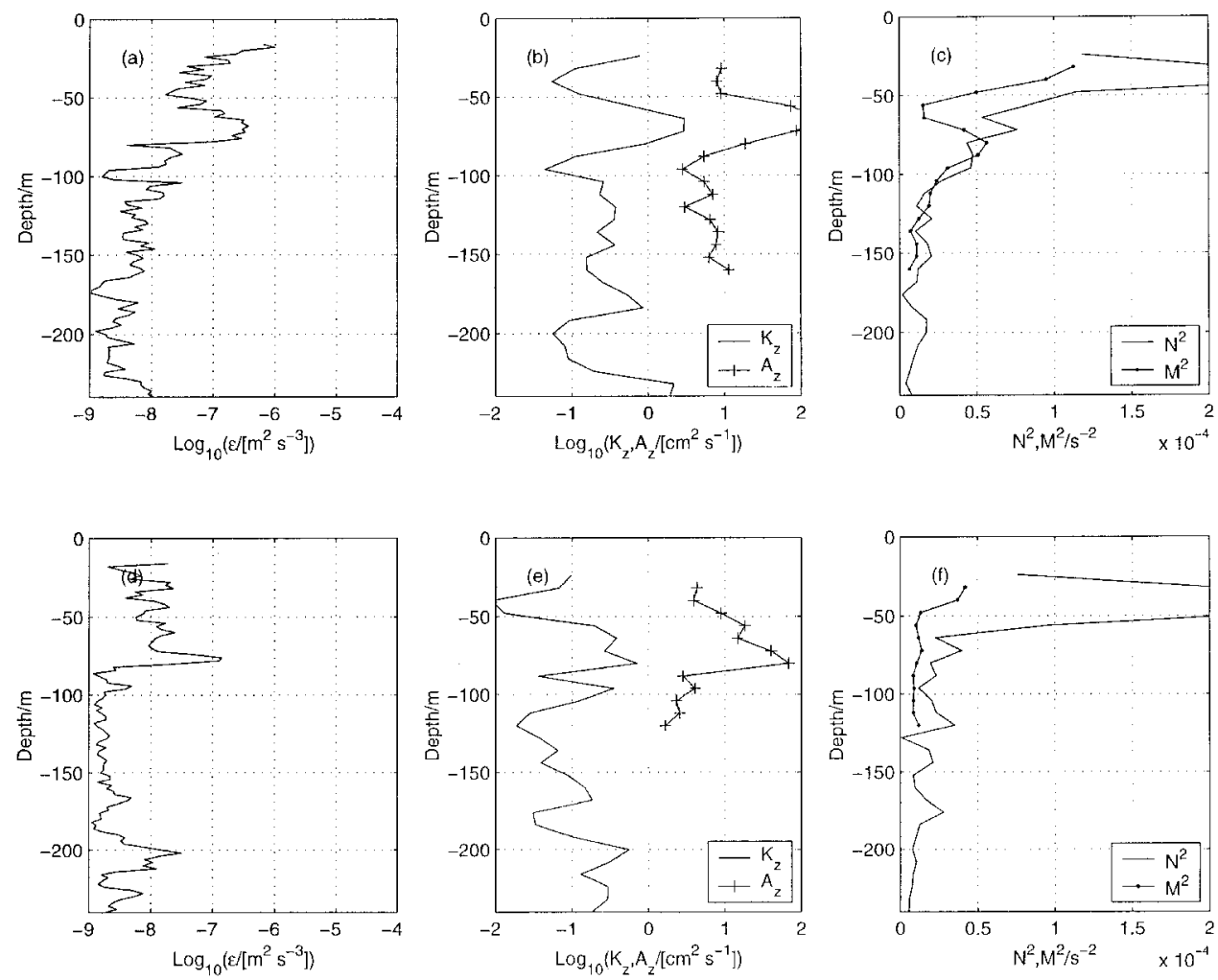

Figure 11. Dissipation (a and d), eddy diffusion and viscosity (b and e), and $N^{2}$ and shear ${ }^{2}$ (c and f) from Series 23 across the filament. The top row were averaged between $1700 \mathrm{~h}$ and $1900 \mathrm{~h}$, to the south of the filament and the bottom row between $2000 \mathrm{~h}$ and $2130 \mathrm{~h}$, on its northern side (see Fig. 8). Dissipation observations were averaged over $2 \mathrm{~m}$ and the other observations over $8 \mathrm{~m}$.

temperature measurements were intermittent and not truly synoptic with those of the ADCP, so $L$ is cautiously assumed to be constant in the upper part of the water column. Since shear, density and dissipation have all been measured, it should be possible to fit them to the local equilibrium relationship used by numerical models (A9):

$$
\alpha M^{2}+\beta N^{2}-\varepsilon^{2 / 3}=0
$$

to determine $\alpha$ and $\beta$. Since $\alpha$ and $\beta$ are functions of $L$, it should then be possible to derive an empirical estimate of its length. Furthermore if (16) is a useful description of the TKE balance, then the profiles of $M^{2}, N^{2}$ and $\varepsilon^{2 / 3}$ should be measurably different. These ideas can be tested from the observations.

The measurements were processed as follows. The data sets were first divided into short sections of typically 6 FLY drops or duration of 1 hour. The ADCP shear $(\partial U / \partial z)$ was calculated between neighboring bins (i.e. over $8 \mathrm{~m})$, and $(\partial U / \partial z)^{2}$ was meaned over time 
to give $M^{2}$. Dissipation and $N^{2}$ measurements from the FLY were averaged over $8 \mathrm{~m}$ to match the $M^{2}$ levels, and also meaned over time. This gave three vectors in $\varepsilon, M^{2}$ and $N^{2}$ respectively, which were then subsampled over their common range (normally about $24 \mathrm{~m}$ to $136 \mathrm{~m}$ ). The averaging thus reduced the variability in the observations and put them on scales that are comparable to those used in ocean models. Since we are particularly interested in internal mixing the vertical range also had the advantage of avoiding any boundary layers.

Dissipation appears to be positively correlated with $M^{2}$ on the shelf, although this trend is not so clear in the ocean (Fig. 12). By contrast, $\varepsilon$ does not appear to be negatively correlated with $N^{2}$. 144 observations from the shelf and 240 from the ocean were separately applied to (16), using a least squares fit, to derive estimates of $\alpha$ and $\beta$ (Table 2). There is quite a lot of scatter in the results (see Fig. 12) and the error in $\varepsilon^{2 / 3}$ is quite large (Table 2), but poor accuracy is not surprising given the intermittent nature of turbulence. Some reassurance in gained from the observation that the error on the shelf (where the measurement strategy was more intensive) is half the size of that in the ocean. The values for $\alpha$ and $\beta$ from the two regions are of comparable size although the ratio $\alpha / \beta$ was about 2 on the shelf and 4 in the ocean. These ratios are about the same as the mean values for $R_{G}$ (recall $R_{G}=N^{2} / M^{2}$, and see Table 2) and imply that the size of the $\alpha M^{2}$ and $\beta N^{2}$ contributions to $\varepsilon^{2 / 3}$ in (16) are comparable.

The values of $\alpha$ and $\beta$ relate $L$ by

$$
\alpha=c_{0} L^{4 / 3} / c_{1}^{1 / 3}
$$

and

$$
\beta=-c_{2} L^{4 / 3} / c_{1}^{1 / 3}
$$

(i.e. A10 and A11 in the Appendix). Ideally (17) and (18) should give similar values for $L$, once suitable values for the stability functions, $c_{0}, c_{1}$ and $c_{2}$ have been chosen. These functions allow stable stratification to reduce the local values of $K_{Z}$ and $A_{Z}$ calculated by models. They are often assumed to be constant: for example, Burchard et al. (1997) used $c_{0}=c_{1}=0.5562$ and $c_{2}=0.6985$, from which (17) gives $L=0.20 \mathrm{~m}$ on the shelf and $0.23 \mathrm{~m}$ in the ocean. These lengths are very close to the mean Ozmidov lengths $\left(L_{O}=\right.$ $0.25 \mathrm{~m}$ on the shelf and $0.18 \mathrm{~m}$ in the ocean), which is encouraging.

However, $\beta$ is positive both on the shelf and in the ocean, so $L$ cannot be determined from (18) since $c_{2} / c_{1}^{1 / 3}$ is also positive. Furthermore, in early experiments it was found that $\alpha$ and $\beta$ were very sensitive to the vertical range that was chosen for the fit. This implies that there are some problems with the basic assumptions, which will be discussed in the next section.

\section{Discussion}

The observations have revealed some important differences in the dissipation profiles of the upper $200 \mathrm{~m}$ of the water column between winter mixed and summer stratified conditions. 

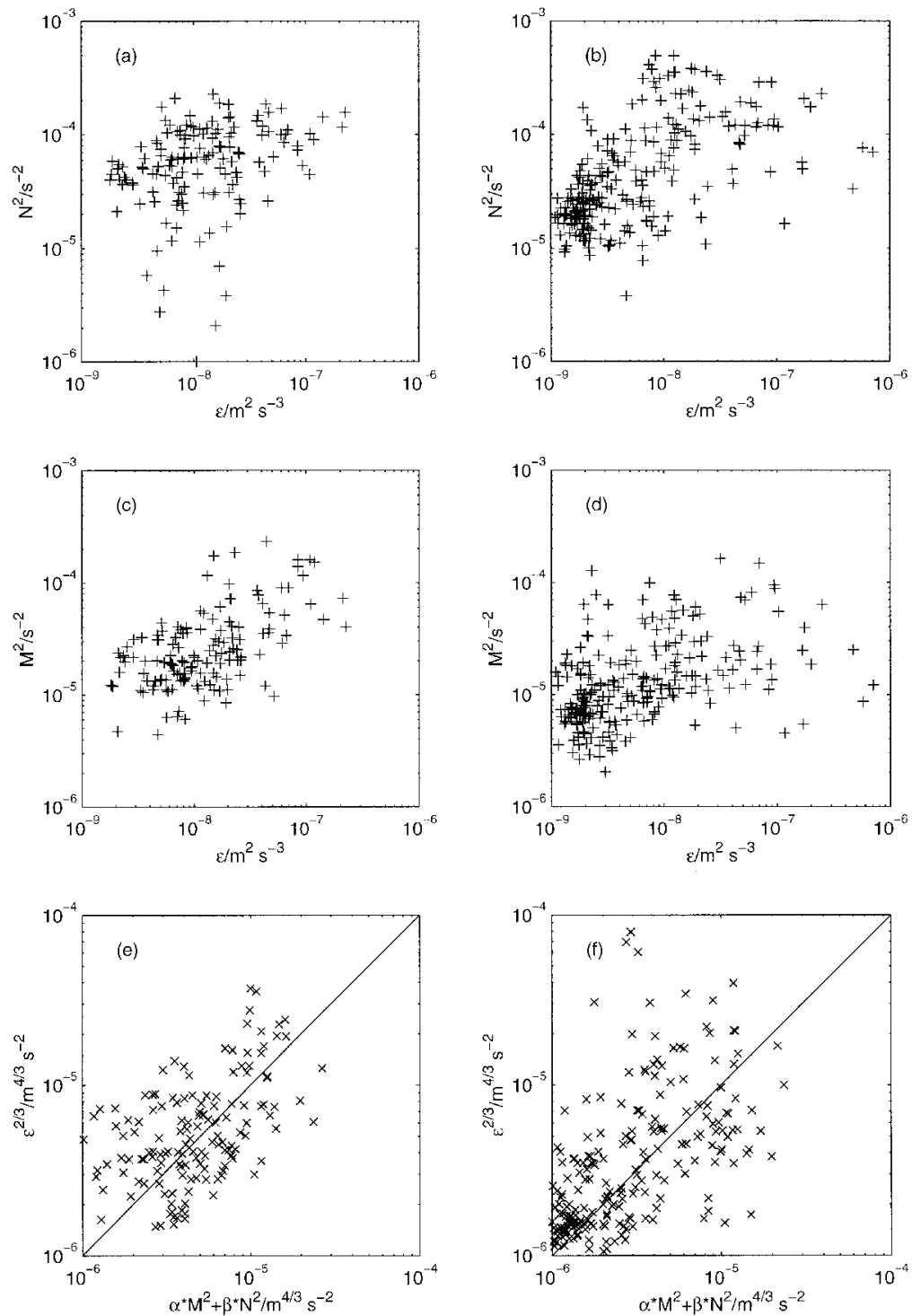

Figure 12. Comparisons between $\varepsilon$ and $N^{2}$ (a and b); $\varepsilon$ and $M^{2}$ (c and d); and $\varepsilon^{2 / 3}$ with estimates of itself based on fitting $N^{2}$ and $M^{2}$ to (16) (e and f). Left-hand panel: on the shelf (Series 16); right-hand panel: in the ocean (all observations from the sites shown in Fig. 7). If the observations fitted (16) exactly, then all data points would lie on the straight lines.

\section{a. The dissipation profile in winter}

The vertical profiles of dissipation during January 1998 suggest that there were two parts to turbulent mixing above the pycnocline. Near the surface was a region of intense mixing in the SBL, which gave way abruptly at a depth of between 18 and $24 \mathrm{~m}$ to a lower region 
where dissipation decreased according to the 'law of the wall.' The depth of the SBL was quite clearly correlated to the wave height and the intensity of mixing, and on the shelf coincided with the depth of the mixed layer observed by the CTD. By contrast, observations of bubble clouds from breaking waves (e.g. Thorpe, 1986, 1992; Plueddemann et al., 1996) have suggested that the SBL should have been about $10 \mathrm{~m}$ shallower. The method of measuring depth by the probe probably caused an overestimate of about $3 \mathrm{~m}$ in the depth of the SBL, but cannot account for all of this discrepancy.

It is possible that the large swell may have had an impact on the depth of the SBL. The waves tended to break along a swell crest, and this aspect of the process may have intensified the mixing that subsequently occurred. In addition, Langmuir cells driven by the swell may have transported the mixing downward in preferential convergence zones (although Plueddemann et al. (1996), for example, found no measurable evidence of such an effect occurring).

It is assumed that the negative buoyancy flux did not affect the observed levels of dissipation. Nevertheless, $B$, which has the same units as dissipation, was similar in magnitude to $\varepsilon$ in the SBL and 2 or 3 orders of magnitude larger than $\varepsilon$ beneath it (see Table 1). Thus, whilst the buoyancy flux was probably the cause of mixing between the base of the SBL and the pycnocline, wind/wave mixing dominated the surface boundary layer. The fact that a 'law of the wall' dissipation profile was observed toward the surface suggests that the mixing time scale for breaking waves (estimated to be of the order of 5 to 10 minutes by Thorpe (1992)) was much shorter than for convection.

Although the 'law of the wall' was evident in the oceanic dissipation profiles, it was not obvious in the velocity profile, nor did it apply on the shelf, where there was a brackish surface pycnocline due to outflow from the local rias. This pycnocline appears to have significantly dampened dissipation levels in the main body of the water column, probably by suppressing the downward diffusion of wind forced turbulence. The enhanced levels of dissipation at the oceanic sites were probably due to the small amount of kinetic energy associated with convection, and may have contributed to the erosion of the deep pycnocline in the northward-moving Navidad (see e.g. Turner, 1979, Chapter 9).

\section{b. The dissipation profile in summer}

In August the water column was stratified and the dissipation profiles appeared to be correlated with local baroclinic shears. Within the internal wave regime on the shelf, one particular mixing event was closely associated with local shears in the thermocline induced by the passage of a series of internal waves. In the ocean, higher dissipation levels were observed in regions where the shear due to geostrophic currents was greatest, for example, on the northern side of the filament. However, the density of measurements was too low to determine the precise cause of this mixing, and it is not possible to say whether it was due to propagating internal waves or some other cause (for example, a local instability). The mean dissipation levels in the body of the water column between $24 \mathrm{~m}$ and about $136 \mathrm{~m}$ 
were slightly higher in the ocean $\left(3 \times 10^{-8} \mathrm{~m}^{2} \mathrm{~s}^{-3}\right)$ than on the shelf $\left(2 \times 10^{-8} \mathrm{~m}^{2} \mathrm{~s}^{-3}\right)$ (see Table 2). These values are significantly less than those observed in winter.

Eddy viscosity levels in the two regions were very similar (about $8 \mathrm{~cm}^{2} \mathrm{~s}^{-1}$ from Eq. 15 and Table 2) but, since the shelf was more strongly stratified than the ocean, the mean eddy diffusion (from Eq. 14) was about three times higher on the shelf $\left(0.37 \mathrm{~cm}^{2} \mathrm{~s}^{-1}\right)$ than in the ocean $\left(0.13 \mathrm{~cm}^{2} \mathrm{~s}^{-1}\right) . P_{R}$ was about 60 in the ocean and about 20 on the shelf which, following McEwan (1983), suggests that mixing events were more frequent on the shelf than in the ocean. At an anecdotal level, this suggestion appears to be borne out by the observations - specific internal wave mixing events were clearly seen to occur on the shelf.

\section{c. Parameterization of mixing in models}

An investigation to derive a mixing length that would be comparable to one used in a turbulence closure model has been made from the observations. This investigation was only partially successful in that the mean length scale derived from the profile of vertical shear, $L$, is comparable to the Ozmidov length, $L_{O}$, which is based on stratification. However, modelers often use both shear and stratification to derive $\varepsilon$ (see 16), on the understanding that turbulence is essentially anisotrophic and that the vertical scale of mixing should shorten as stratification intensifies. In the present case it was found that it is not possible to use the observations to derive values of $\alpha$ and $\beta$ from (16) that could give consistent estimates of $L$ from (17) and (18). In nearly every case a positive value for $\beta$ was found, suggesting that stratification actually enhances mixing. One problem seems to be that, both on the shelf and in the filament, $N^{2}$ and $M^{2}$ were not strictly orthogonal (see for example Figs $9 \mathrm{c}$ and $11 \mathrm{c}$, and compare them with the dissipation profiles, Figs. 9a and 11a), so that it is not possible to differentiate the contributions that each made to $\varepsilon^{2 / 3}$. It is unlikely that the calculations are sensitive to the assumption that the stability functions are constant. For stable stratification the ratio $c_{0} / c_{2}$ remains roughly constant (e.g. Galerpin $e t$ $a l ., 1998$ ), so that whilst the inclusion of variable stability functions would lead to different estimates of $L$, they would not make $\alpha M^{2}$ and $\beta N^{2}$ orthogonal. Thus $B$ would almost certainly still appear to be a source rather than a sink for mixing.

With this in mind buoyancy dependency was removed from (16) and $\alpha$ calculated from

$$
\alpha M^{2}-\varepsilon^{2 / 3}=0
$$

Neglecting $\beta$ had no effect on the accuracy of the estimates of $\varepsilon^{2 / 3}$ (Table 2), but increased the size of $L$ to between 0.3 (shelf) and $0.35 \mathrm{~m}$ (ocean). Thus $L$ (shelf) was still comparable to $L_{O}$ (shelf), but $L$ (ocean) was twice $L_{O}$ (ocean). However, given the fairly poor accuracy of these estimates, the length scales can probably still be considered reasonably accurate (within, say, $\pm 50 \%$ ).

It is likely that similar $N^{2}$ and $M^{2}$ profiles occur quite frequently, particularly in places where it may be important to get a good estimate of $\varepsilon$. For example, in the ocean vertical stratification is often associated with fronts (horizontal stratification), which through the thermal wind equation, $\partial U / \partial z=-g / f \rho(\partial \rho / \partial y)$ where $f$ is the internal frequency and $y$ the 

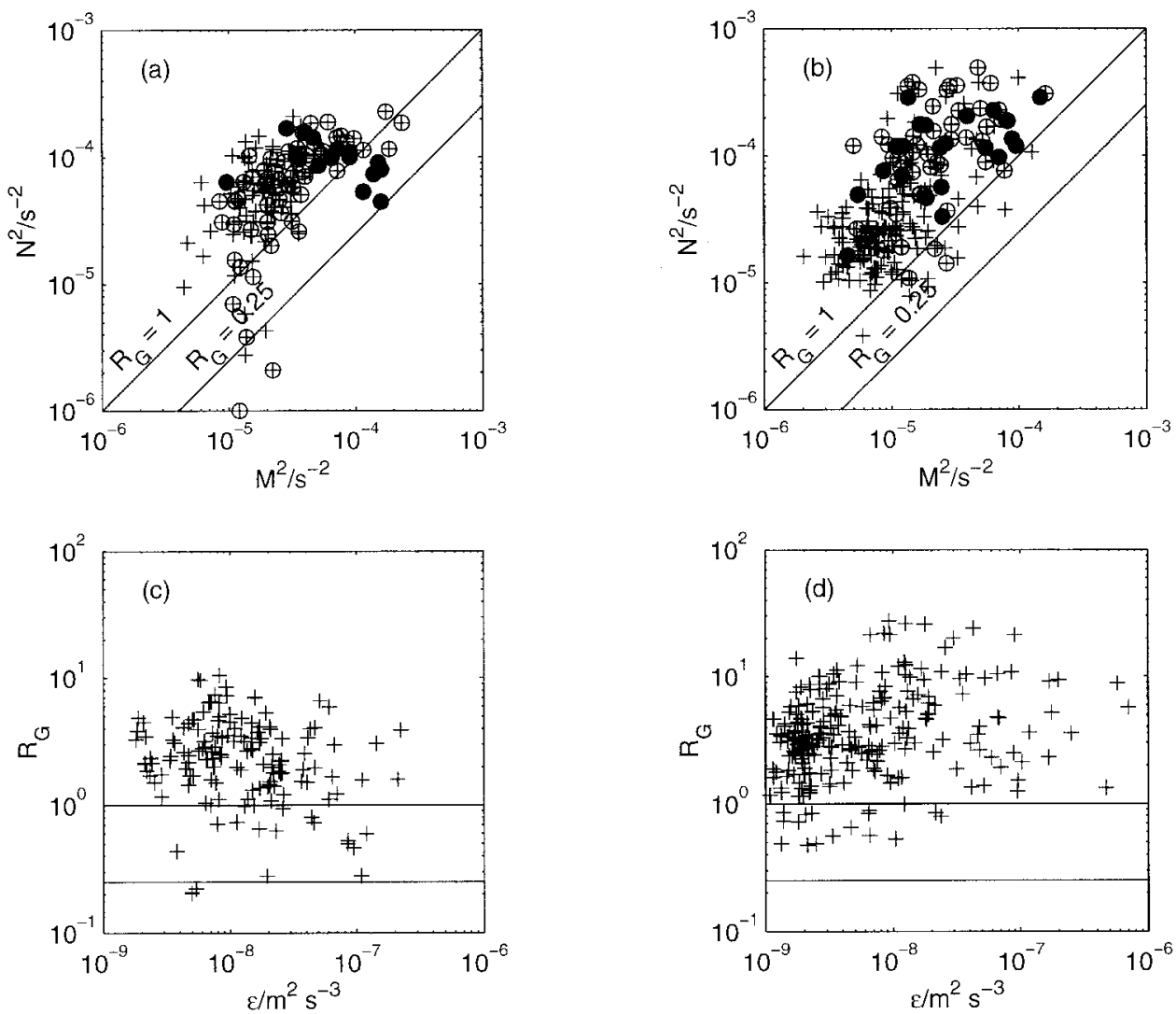

Figure 13. $N^{2}$ vs. $M^{2}$ (a and b), and $R_{G}$ vs. $\varepsilon$ (c and d). As with Figure 12, the left-hand panel is over the shelf and the right-hand one in the ocean. The two lines show $R_{G}=0.25$ and 1 . The symbols in (a) and (b) are: '+' $-\varepsilon<10^{-8} \mathrm{~m}^{2} \mathrm{~s}^{-3}$; ' $\oplus$ ' $-10^{-8}<\varepsilon<5 \times 10^{-8} \mathrm{~m}^{2} \mathrm{~s}^{-3}$; ' $\bigcirc$ ' $-\varepsilon>5 \times$ $10^{-8} \mathrm{~m}^{2} \mathrm{~s}^{-3}$. Each data point was an average over roughly 1 hour in time and $8 \mathrm{~m}$ in space.

co-ordinate normal to $U$, creates vertical shear. The filament structure encountered during the summer cruise is one such example of this. On the other hand a stratified shelf is likely to be affected by internal tides generated at its edge. On the Iberian shelf (as in many other places) the internal tide and associated high frequency internal waves are of mode 1 form, which means that they have their highest shear in the thermocline. Neither of these examples will result in $N^{2}$ and $M^{2}$ profiles that are clearly orthogonal.

Notwithstanding the problem of orthogonality, there may also be a physical effect that has reinforced the appearance of $B$ as being a source of mixing, rather than being neutral or a sink. It is noticeable that although on the shelf, mixing tends to be enhanced in regions of high shear, it is not exclusively associated with low values of $R_{G}$, and it seems to be just as important that $N^{2}$ is large (Fig. 13). The situation in the ocean, where none of the high values of $\varepsilon$ was associated with low values of $R_{G}$, appears to be even more anomalous. It 
would seem on the face of it, therefore, that at the scales we are considering here, $R_{G}$ is not an important parameter of mixing in the ocean.

Although part of the problem may be to do with the intermittency of mixing, there may be something else involved in the picture. Vertical and temporal averaging on the scales used in the observations, and by oceanic models, effectively smooth out small-scale internal waves, which are almost ubiquitous in the presence of stratification. Thus any suppression of the vertical component of turbulence by an increase in stratification will tend to be opposed by an increase in mixing due to subgrid processes such as high frequency and high wavenumber internal waves and instabilities. (This point is in addition to the separate point made earlier, that over large scales mixing can occur at values of $R_{G}>1$.) The observations support the idea that, although at sufficiently small scales stratification must act as a sink for TKE, at larger scales it will tend to attract mixing energy from internal waves. Thus at the scales employed by models some TKE production processes will be missed and the parameterization of the suppression of TKE by buoyancy thus appears to be arbitrary.

Given the uncertainties that exist here, and the computational overheads required for a model to include buoyancy in its estimate of $\varepsilon$, there would appear to be a good case for assuming $B=0$ in the local equilibrium equation (12) under stable stratification.

Acknowledgments. Satellite images were received by the NERC Dundee Satellite Receiving Station, and processed by Peter Miller at the Plymouth Marine Laboratory Remote Sensing Group in Plymouth The captain and crew of RRS Charles Darwin (cruise CD110 and CD114) are thanked for their help during the experiments. This work was supported by the European Union in the framework of the MAST 3 Programme, contract number MAS3-CT97-0076 (OMEX project). We are very grateful for the helpful comments of an anonymous reviewer, which have resulted in an improved paper.

\section{APPENDIX}

Consider the one-dimensional horizontal momentum equation

$$
\frac{\partial U}{\partial t}=\frac{\partial}{\partial z}\left(A_{z}(z, t) \frac{\partial U}{\partial z}\right)+(\text { other terms) }
$$

The standard procedure for representing (A1) in a numerical model is to split the scales of motion into two parts. Large-scale velocities, $U$, exist on much larger scales than the grid size. Velocities at smaller scales than this are 'turbulent' and parameterized as coefficients of viscosity $\left(A_{Z}(z, t)\right)$. The problem for modelers is to decide how to parameterize $A_{Z}$. In turbulence closure schemes, the assumption is made that $A_{Z}$ can be determined from the vertical distribution of $U$.

The argument is advanced as follows (see e.g. Burchard et al., 1998). It is assumed that $A_{Z}$ has the form

$$
A_{Z}=c_{0} b^{1 / 2} L
$$


where $c_{0}$ is a constant; $b$ is the subgrid scale turbulent kinetic energy (TKE); and $L$ is a suitable length scale. The TKE can be derived from

$$
\frac{\partial b}{\partial t}=\frac{\partial}{\partial z}\left(A_{Z} \frac{\partial b}{\partial z}\right)+A_{Z} M^{2}-K_{Z} N^{2}-\varepsilon
$$

where $M^{2}=(\partial U / \partial z)^{2} ; K_{Z}$ is the eddy diffusion coefficient, $N^{2}$ is the buoyancy frequency; and $\varepsilon$ is the turbulence energy dissipation defined as

$$
\varepsilon=\frac{c_{1} b^{3 / 2}}{L}
$$

where $c_{1}$ is a constant. Diffusion is assumed to have similar form to viscosity, i.e.:

$$
K_{Z}=c_{2} b^{1 / 2} L
$$

The challenge to modelers is to determine a computationally efficient parameterization for $L$.

In order to simplify the problem it is normally assumed that a local equilibrium pertains, i.e.

$$
0=A_{Z} M^{2}-K_{Z} N^{2}-\varepsilon
$$

or

$$
P=B+\varepsilon
$$

where $P=A_{Z} M^{2}$ is the rate of production of TKE; and $B=K_{Z} N^{2}$ is the rate of work against buoyancy (in raising the potential energy of the water column).

In mixed waters, $N^{2}=0$, and (A7) becomes

$$
\varepsilon=P
$$

so that the rate of production of TKE is balanced by the rate of dissipation. In these circumstances it would appear that it is possible to determine appropriate values for $L$ that result in reasonable estimates of $A_{Z}$ and $K_{Z}$.

When the water column is stratified, however, the problem becomes more complicated. Superficially it would seem that if the stability functions $c_{0}, c_{1}$ and $c_{2}$ can be determined empirically, then it should not be too difficult to define an $L$ to close the problem. Suitable values for these functions are discussed in the main text.

In the present work we search for $L$ by processing the summer cruise observations as though they had been derived from a model. This seems to be a reasonable thing to do given that the observations of dissipation and its related variables

i) had vertical scales that were similar to the resolution of large scale numerical models, and 
ii) were averaged over periods of time that are similar to the rate at which changes take place in numerical models.

We thus eliminate $b, A_{Z}$ and $K_{Z}$ from (A2), (A4), (A5) and (A6) to give

$$
\varepsilon^{2 / 3}=\alpha M^{2}+\beta N^{2}
$$

where

$$
\alpha=c_{0} L^{4 / 3} / c_{1}^{1 / 3}
$$

and

$$
\beta=-c_{2} L^{4 / 3} / c_{1}^{1 / 3} .
$$

Our aim is then to fit (A9) to observations of $M^{2}, N^{2}$ and $\varepsilon$ with $\alpha$ and $\beta$ as free parameters, in the hope that $\alpha$ and $\beta$ will give consistent estimates of $L$ for typical stability functions.

\section{REFERENCES}

Anis, A. and J. N. Moum. 1994. Surface wave-turbulence interactions: Scaling $\varepsilon(z)$ near the sea surface. J. Phys. Oceanogr., 25, 2025-2045.

Barton, E. D, R. Torres, M. E. Inall and T. J. Sherwin. 2001. Vertical structure, turbulent mixing and fluxes during Lagrangian observations of an upwelling filament system off Northwest Iberia. Prog. Oceanogr., 51, 249-267.

Burchard, H., O. Petersen and T. P. Rippeth. 1998. Comparing the performance of the MellorYamada and the $k-\varepsilon$ two equation turbulence models. J. Geophys. Res.,(C5) 103, 10,543-10,554.

Craig, P. D. and M. L. Banner. 1994. Modelling wave-enhanced turbulence in the ocean surface layer. J. Phys. Oceanogr., 24, 2546-2559.

Crawford, W. R. 1976. Turbulent energy dissipation in the Atlantic Equatorial Undercurrent. PhD Thesis, University of British Columbia, 149 pp.

Davis, R. E. 1996. Sampling turbulent dissipation. J. Phys. Oceanogr., 26, 341-358.

Dewey, R. K., W. R. Crawford, A. E. Gargett and N. S. Oakey. 1987. A microstructureinstrument for profiling oceanic turbulence in coastal bottom boundary layers. J. Atmos. Ocean Tech., 4, 288-297.

Dillon, T. M. 1982. Vertical overturns: A comparison of Thorpe and Ozmidov length scales. J. Geophys. Res.,(C12) 87, 9601-9613.

Galerpin, G., L. H. Kantha, S. Hassid and A. Rosati. 1988. A quasi-equilibrium turbulent kinetic energy model for geophysical flows. J. Atmos. Sci., 45, 55-62.

Gargett, A. E. and G. Holloway. 1984. Dissipation and diffusion by internal wave breaking. J. Mar. Res., 42, 15-27.

Joint, I, M. E. Inall, R. Torres, F. G. Figueiras, X. A. Alvarez and M. Woodward. 2001. Two Lagrangian experiments in the Iberian upwelling system: tracking an upwelling event and an offshore filament. Prog. Oceanogr., 51, 221-248.

Large, W. G. and S. Pond. 1981. Open ocean momentum flux measurements in moderate to strong winds. J. Phys. Oceanogr., 11, 324-336.

Linden, P. F. 1979. Mixing in stratified fluids. Geophys. Astrophys. Fluid Dyn., 13, 3-23.

McEwan, A. D. 1983. Internal mixing in stratified fluids. J. Fluid Mech., 128, 59-80.

Niiler, P. P. and E. B. Kraus. 1977. One-dimensional models of the upper ocean, in Modeling and Prediction of the Upper Layers of the Ocean, B. Kraus, ed., Pergamon, Oxford, 143-172. 
Oakey, N. S. and J. A. Elliott. 1982. Dissipation within the surface mixed layer. J. Phys. Oceanogr., 12, 171-185.

Osborn, T. R. 1974. Vertical profiling of velocity microstructure. J. Phys. Oceanogr., 4, 109-115.

1980 Estimates of the local rate of vertical diffusion from dissipation measurements. J. Phys. Oceanogr., 10, 83-89.

Phillips, O. M. 1977. The Dynamics of the Upper Ocean, Cambridge University Press, Cambridge, $336 \mathrm{pp}$.

Plueddemann A. J., J. A Smith, D. M. Farmer, R. A. Weller, W. R. Crawford, R. Pinkel, S. Vagle and A. Gnanadesikan. 1996. Structure and variability of Langmuir circulation during the Surface Waves Processes Program. J. Geophys. Res., (C2) 101, 3525-3543.

Simpson, J. H. and D. G. Bowers 1984. The role of tidal stirring in controlling the seasonal heat cycle in shelf seas. Annales Geophysic., 2, 411-416.

Tennekes, H. and J. L. Lumley. 1997. A First Course in Turbulence, MIT Press, 293 pp.

Terray, E. A., M. A. Donelan, Y. C. Agrawal, W. M. Drennan, K. K. Kahma, A. J. Williams III, P. A Hwang and S. A. Kitaigorodskii. 1996. Estimates of kinetic energy dissipation under breaking waves. J. Phys. Oceanogr., 26, 792-807.

Thorpe, S. A. 1986. Measurements with an automatically recording inverted echo sounder; ARIES and the bubble clouds. J. Phys. Oceanogr., 16, 1462-1478.

1992. Bubble clouds and the dynamics of the upper ocean. Quart. J. Royal Meteor. Soc., 118, Part A, 1-22.

Torres, R. and E. D. Barton 1999. Charles Darwin Cruise 114: Acoustic Doppler Current Profiler report. Data Report, University of Wales, Bangor, $10 \mathrm{pp}+$ figures.

Turner, J. S. 1979. Buoyancy Effects in Fluids, Cambridge University Press, Cambridge, 368 pp. 